\title{
Scanning mutagenesis of RNA-binding protein ProQ reveals a quality control role for the Lon protease
}

\author{
YOUSSEF EL MOUALI, ${ }^{1,2}$ FALK PONATH, ${ }^{2}$ VINZENT SCHARRER, ${ }^{1}$ NICOLAS WENNER, ${ }^{3,4}$ \\ JAY C.D. HINTON, ${ }^{3}$ and JÖRG VOGEL ${ }^{1,2}$ \\ ${ }^{1}$ Institute of Molecular Infection Biology (IMIB), University of Würzburg, D-97080 Würzburg, Germany \\ ${ }^{2}$ Helmholtz Institute for RNA-based Infection Research (HIRI), Helmholtz Centre for Infection Research (HZI), D-97080 Würzburg, Germany \\ ${ }^{3}$ Institute of Infection, Veterinary and Ecological Sciences, University of Liverpool, L7 3EA Liverpool, United Kingdom
}

\begin{abstract}
The FinO-domain protein ProQ belongs to a widespread family of RNA-binding proteins (RBPs) involved in gene regulation in bacterial chromosomes and mobile elements. While the cellular RNA targets of ProQ have been established in diverse bacteria, the functionally crucial ProQ residues remain to be identified under physiological conditions. Following our discovery that ProQ deficiency alleviates growth suppression of Salmonella with succinate as the sole carbon source, an experimental evolution approach was devised to exploit this phenotype. By coupling mutational scanning with lossof-function selection, we identified multiple ProQ residues in both the amino-terminal FinO domain and the variable carboxy-terminal region that are required for ProQ activity. Two carboxy-terminal mutations abrogated ProQ function and mildly impaired binding of a model RNA target. In contrast, several mutations in the FinO domain rendered ProQ both functionally inactive and unable to interact with target RNA in vivo. Alteration of the FinO domain stimulated the rapid turnover of ProQ by Lon-mediated proteolysis, suggesting a quality control mechanism that prevents the accumulation of nonfunctional ProQ molecules. We extend this observation to Hfq, the other major sRNA chaperone of enteric bacteria. The Hfq Y55A mutant protein, defective in RNA-binding and oligomerization, proved to be labile and susceptible to degradation by Lon. Taken together, our findings connect the major AAA+ family protease Lon with RNA-dependent quality control of $\mathrm{Hfq}$ and ProQ, the two major sRNA chaperones of Gram-negative bacteria.
\end{abstract}

Keywords: RNA-binding proteins; ProQ; Hfq; Lon protease; protein stability

\section{INTRODUCTION}

Globally acting RNA-binding protein (RBPs) that work in concert with small regulatory RNAs (sRNAs) play crucial roles in post-transcriptional control in both eukaryotes and prokaryotes (Gorski et al. 2017). Three RBPs are highly conserved in Gram-negative bacteria (Holmqvist and Vogel 2018): the translational repressor CsrA (a.k.a. RsmA), which itself is regulated by decoy sRNAs (Romeo and Babitzke 2018), and the RNA chaperones $\mathrm{Hfq}$ and ProQ, both of which regulate mRNAs via base-pairing sRNAs (Vogel and Luisi 2011; Olejniczak and Storz 2017; Kavita et al. 2018; Romeo and Babitzke 2018; Holmqvist et al. 2020). The in vivo targetomes of these central RBPs have been mapped extensively in several bacteria (Zhang et al. 2003; Sittka et al. 2007, 2008; Chao et al. 2012;

\footnotetext{
${ }^{4}$ Present address: Biozentrum, University of Basel, 4056 Basel, Switzerland

Corresponding author: joerg.vogel@uni-wuerzburg.de

Article is online at http://www.rnajournal.org/cgi/doi/10.1261/rna. 078954.121. Freely available online through the RNA Open Access option.
}

Tree et al. 2014; Attaiech et al. 2016; Holmqvist et al. 2016, 2018; Melamed et al. 2016, 2020; Smirnov et al. 2016; Heidrich et al. 2017; Potts et al. 2017; Bauriedl et al. 2020; losub et al. 2020; El Mouali et al. 2021) revealing that each interacts with hundreds of different transcripts from diverse cellular pathways. However, while their regulatory roles and their associated sRNAs become better understood, we still know little about the biogenesis and turnover of these central RPBs, and the mechanisms that ensure that they do not accumulate intracellularly as nonfunctional RBPs. In this study, we propose a quality control mechanism that involves the degradation of ProQ when it fails to associate with RNA.

ProQ is the least understood of the three global RBPs. In Salmonella enterica serovar Typhimurium (henceforth, Salmonella), ProQ is an abundant $25 \mathrm{kDa}$ protein with an amino-terminal domain (NTD, residues 1-119) and a

(C) 2021 El Mouali et al. This article, published in RNA, is available under a Creative Commons License (Attribution-NonCommercial 4.0 International), as described at http://creativecommons.org/licenses/ by-nc/4.0/. 
carboxy-terminal domain (CTD, 176-228 residues) connected by a disordered $\sim 50$-aa linker region (Smirnov et al. 2016; Gonzalez et al. 2017). The targets of ProO include $\sim 50$ sRNAs that tend to be more structured than Hfq-bound sRNAs (Smirnov et al. 2016; Holmqvist et al. 2018), and several hundred mRNAs, which are primarily recognized at their $3^{\prime}$ end (Holmqvist et al. 2018); many of these interactions are conserved between Salmonella and Escherichia coli (Holmqvist et al. 2018; Melamed et al. 2020). Target recognition is thought to be determined by the NTD, a region that contains a FinO domain (PFAM04352) and was shown to mediate RNA binding of other investigated members of the family of ProQ/FinOlike proteins (Ghetu et al. 1999; Chaulk et al. 2011; Attaiech et al. 2016; Bauriedl et al. 2020; Gerovac et al. 2020; El Mouali et al. 2021). In addition, the NTD was sensitive to mutations in a bacterial three-hybrid (B3H) assay designed to score ProO binding to selected bait RNAs (Pandey et al. 2020). In contrast, the role of the CTD is unclear. A truncated ProQ protein lacking the variable carboxy-terminal region showed weaker binding to some targets in vitro as compared to full-length ProO (Stein et al. 2020), but the importance of the CTD for in vivo activity of ProQ is yet to be demonstrated.

Forward genetics, using saturation mutagenesis coupled with phenotypic screening, is a powerful tool to assess the importance of individual regions and amino acid residues for the in vivo function of a protein of interest (Fowler et al. 2014). However, despite the established global activity of ProQ as an RBP, the known phenotypes of Salmonella $\Delta$ proQ strains (e.g., impaired motility and reduced invasion of eukaryotic cells [Westermann et al. 2019]) were insufficiently robust for in vivo screens under physiological conditions. Inspired by the reported growth suppression of Salmonella with succinate as the sole carbon source (Hersch et al. 2021), we discovered that deletion of the proQ gene generated a gain-of-function phenotype that permitted rapid growth on minimal media containing succinate. Using this strong phenotype for a saturation mutagenesis screen, we have mapped crucial residues for ProO function in vivo. We establish a link between RNA binding ability and protein stability, suggesting a quality control mechanism in which nonfunctional ProQ is rapidly removed from the cell by the major ATP-dependent protease Lon.

\section{RESULTS}

\section{ProQ suppresses growth in succinate-containing media}

Succinate has been identified as an important carbon source for Salmonella during colonization of the murine gastrointestinal tract (Spiga et al. 2017), and plays an important role during macrophage infection (Jiang et al. 2021; Rosenberg et al. 2021). Wild-type S. Typhimurium displays an extended lag phase and a slow doubling time when grown in media with succinate as the sole carbon source (Hersch et al. 2021). Because deletion of the $S$. Typhimurium proQ gene is known to modulate expression of hundreds of mRNAs and sRNAs (Smirnov et al. 2016), we investigated whether ProQ modulated the succinate-dependent in vitro growth phenotype. We discovered that genetic inactivation of proQ increases the growth rate of Salmonella when succinate is the sole carbon source, either on agar plates or under microaerobic conditions in liquid media (Fig. 1A,B).

This gain-of-function phenotype is shown in the wellcharacterized $\triangle$ proQ strain of S. Typhimurium SL1344 (Smirnov et al. 2016; Westermann et al. 2019; El Mouali et al. 2021), and we confirmed that plasmid complementation fully restored the succinate-dependent growth suppression by ProO (Fig. 1A,B). The molecular basis of this conditional growth permissiveness is unknown, but our preliminary experiments point toward a derepression of the TCA cycle in the absence of ProQ (Supplemental Fig. S1). The remarkable robustness of this succinate-dependent growth phenotype provided the first unequivocal readout of functionality of Salmonella ProQ in vivo.

\section{Deep mutational scanning of ProQ in vivo}

To obtain a functional map of ProQ residues in vivo, we performed saturation mutagenesis of the Salmonella proQ open reading frame (ORF). To this end, we generated libraries of ProQ expression plasmids ( $\mathrm{PProQ}$, proQ expressed under its native promoter) with random mutations in the coding sequence (CDS) of proO that were introduced into the $\triangle p r o Q$ strain. The plasmids that allowed microaerobic growth in M9-succinate media were sequenced to identify amino acid substitutions in the ProO protein. Importantly, wild-type Salmonella, the $\Delta$ proQ strain alone or the latter complemented with proQ on a plasmid all displayed similar fitness when grown in LB media, with only a minor growth defect associated with ProO expression from a plasmid (Fig. 1A). Thus, LB provided a neutral growth condition for constructing and maintaining the mutant libraries.

Mutant variants of pro $Q$ were generated by error prone PCR, cloned and expanded in E. coli TopF cells to ultimately be transformed within the $\triangle$ proQ strain (Supplemental Fig. S2). To overcome the limited read length of Illumina sequencing (300 bp pair-end sequencing), we generated three mutant libraries that focused on different regions of the 228-aa ProO protein: LIB1, LIB2, and LIB3, covering amino acids $1-81,73-155$, and $155-227$, respectively (Fig. 1C). The mutants for each of the libraries were combined individually to obtain "input" pools for LIB1, LIB2, and LIB3, respectively. We then screened a total of 30,000 individual colonies (containing $~ 5000$ variants, see Materials and Methods) for each of the "input" pools 
A

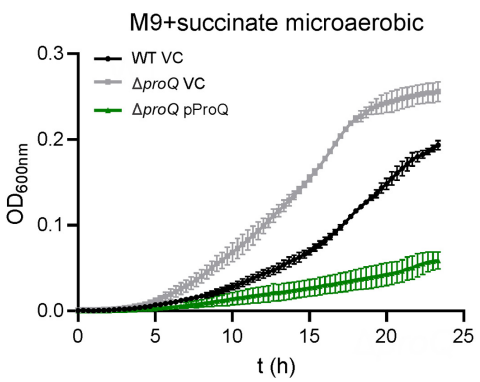

C

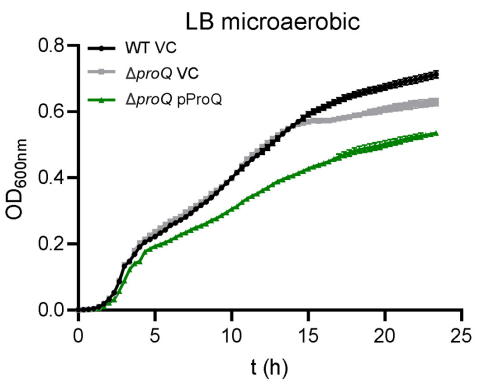

Library selection

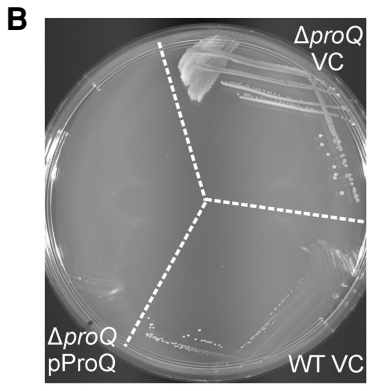

OUTPUT LB
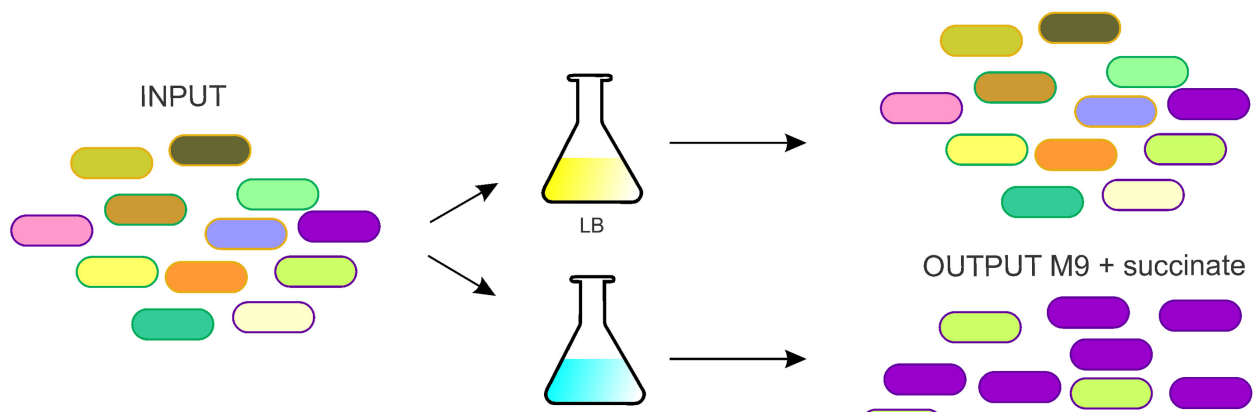

OUTPUT M9 + succinate

M9 + succinate
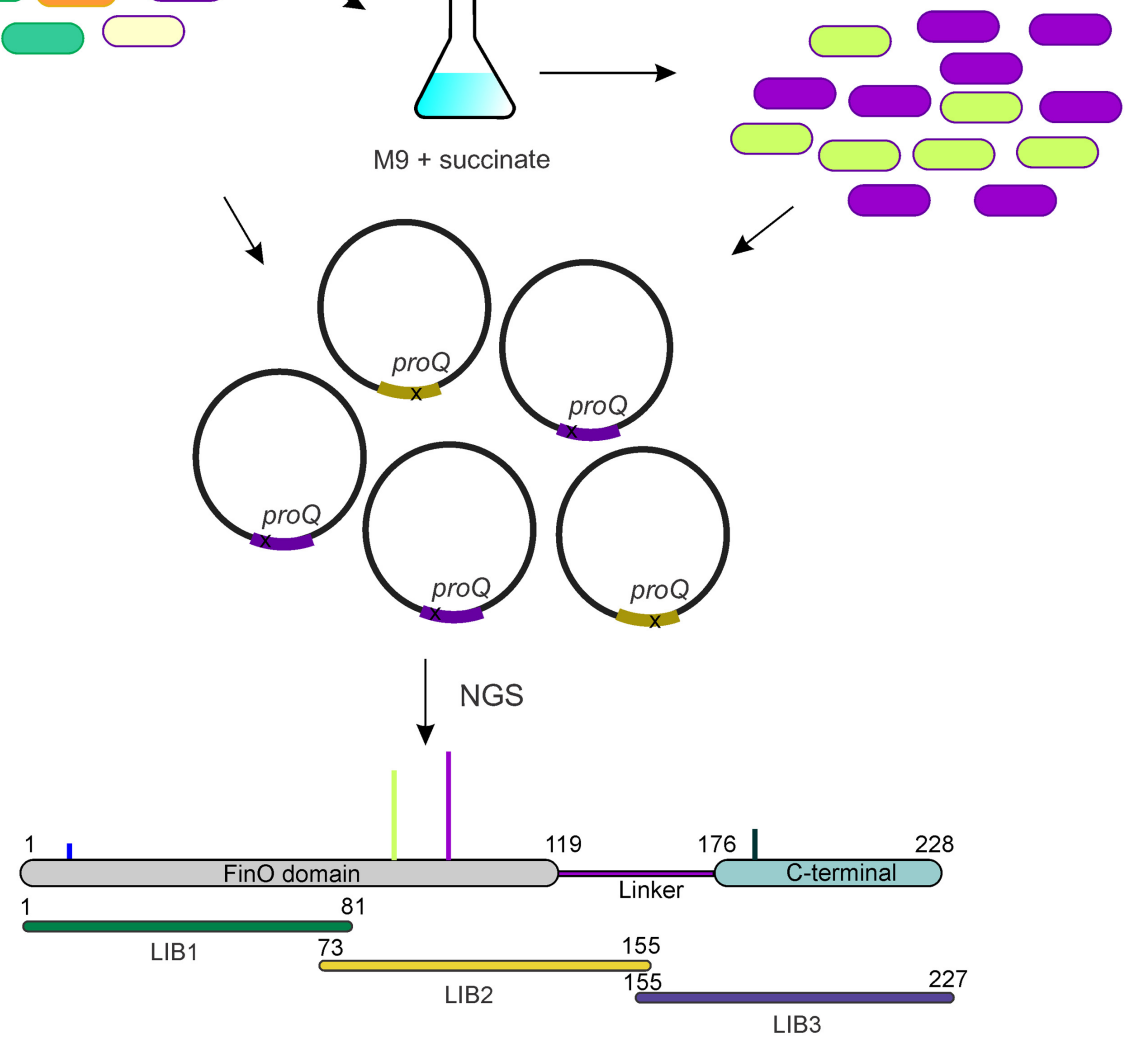

output vs input

FIGURE 1. ProQ represses succinate utilization in Salmonella. (A) Growth of Salmonella WT, $\Delta$ proQ, and $\Delta$ proQ pProQ in a $96-$ well plate Tecan. Strains were inoculated to an $\mathrm{OD}_{600 \mathrm{~nm}} 0.01$ and grown in a 96-well plate in M9 $40 \mathrm{mM}$ succinate (or LB) at $37^{\circ} \mathrm{C}$ for $24 \mathrm{~h}$ without shaking. VC: presence of the empty pZE12vector (pJV300). Average values of three replicates with the standard deviation (SD) are shown. (B) Growth of Salmonella enterica SL1344 WT and $\Delta$ proQ derivative strain in solid agar media M9 with $40 \mathrm{mM}$ succinate as sole carbon source. Single colony was streaked and plates incubated overnight at $37^{\circ} \mathrm{C}$. (C) Deep mutational scanning schematic workflow. The input represents a library of mutants expressed from pZE12-ProQ ( $p$ ProQ) within a $\triangle p r o Q$ strain. The libraries were selected in parallel in nonselective media (LB) and selective media (M9 $40 \mathrm{mM} \mathrm{Na-succinate).} \mathrm{The} \mathrm{cultures} \mathrm{were} \mathrm{incubated} \mathrm{without} \mathrm{shacking} \mathrm{at} 37^{\circ} \mathrm{C}$ for $24 \mathrm{~h}$. Form the resulting cultures, plasmid content was extracted and used as template for library preparation and Mi-seq $2 \times 300 \mathrm{bp}$ sequencing. In the bottom, schematic representation of ProO protein organization and coordinates of ProQ mutant libraries. LIB1 1-81 aa, LIB2 73-155 aa, and LIB3 155-227 aa. 
for growth (i.e., loss of ProQ function) in liquid M9-succinate media for $24 \mathrm{~h}$ without aeration (Fig. 1C). In parallel, the "input" pools were grown in LB to determine whether ProQ variants accumulated due to genetic drift, independent of the selection for ProO functionality. We will refer to these pools from growth in LB or M9-succinate media as "output LB" or "output M9," respectively (Fig. 1C).

Sequencing the input and output pools, we detected thousands of variants, including 93 mutants that carried stop mutations. Only the single nonsynonymous substitutions were considered in the biocomputational analysis: 1056 mutants for LIB1; 1164 for LIB2; and 1032 for LIB3. Of note, single substitutions for all individual residues of ProQ were detected in both the input (Supplemental Table S2) and output libraries. For each of the three different libraries, a prominent enrichment ( $Z$-score $\geq 30$, enrich score $\geq 1.4$ ) of amino acid substitutions in the output versus the input was only observed after selection in M9-succinate media (Fig. 2A-F). Thus, these enriched residues represented candidate mutants of ProO protein with impaired function in vivo.

\section{Both the amino terminus and carboxyl terminus of ProO are essential for in vivo function}

LIB1 and LIB2 collectively cover the amino-terminal FinO domain of ProQ, and all the 27 top-enriched (Z-score $\geq 30$, enrich score $\geq 1.4$ ) mutations from the output M9 pool fall within this domain, except $\operatorname{Pro}_{P 135 s}$ and $\operatorname{Pro}_{K 148 E}$ in the linker region (Fig. 2G). Importantly, although the selected residues appeared to be scattered over the FinO domain in terms of primary sequence, they spatially clustered in the tertiary structure and overlapped with the proposed RNA interaction face of ProQ (see further below). Intriguingly, the third library (LIB3) also predicted numerous residues important for ProQ function; these clustered in a 40 -aa region that
A

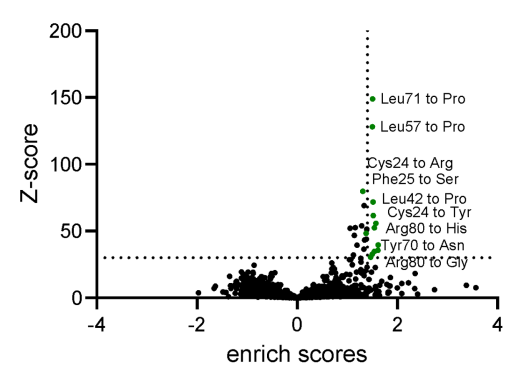

B

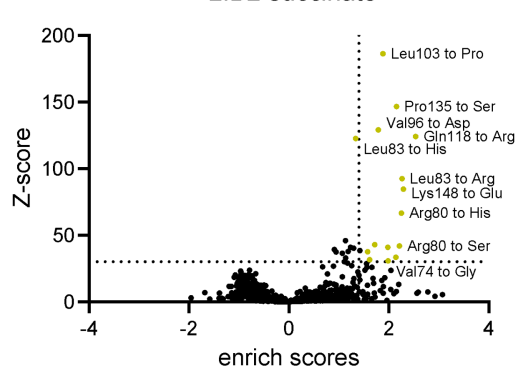

C

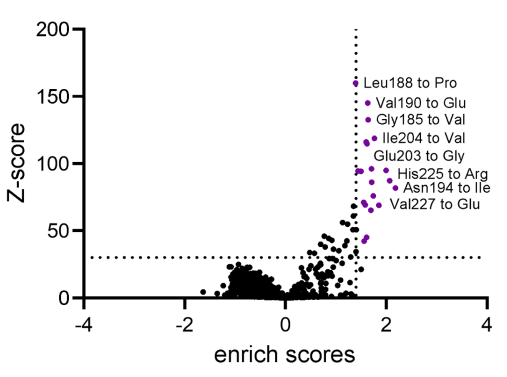

D

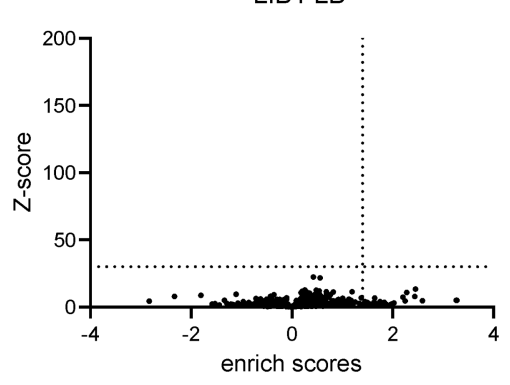

E

$\mathbf{F}$

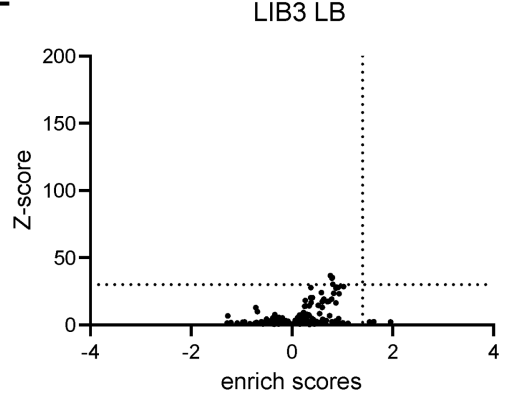

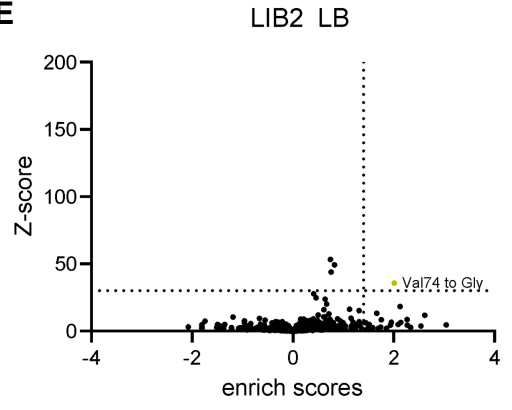

G

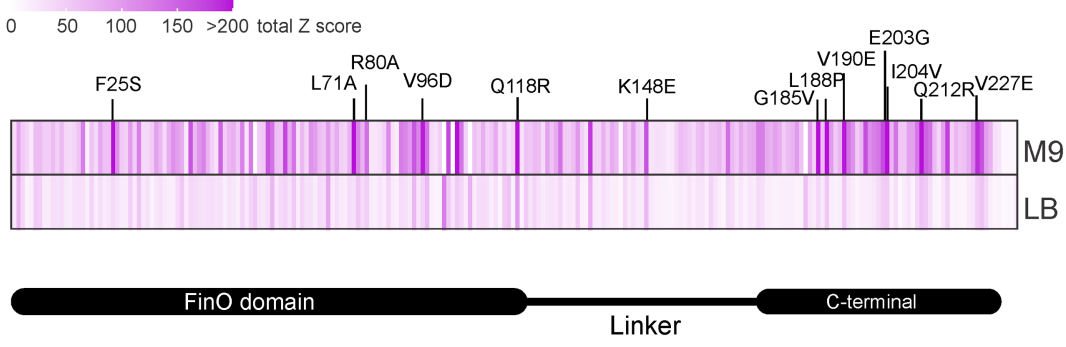

FIGURE 2. ProQ variants enrichment. (A) Amino acid substitutions enriched in the output in M9 succinate (selective media) when compared to the input for LIB1 (1-81 aa). In green highlighted significantly enriched residues substitutions. (B) Amino acid substitutions enriched in the output in M9 succinate (selective media) when compared to the input for LIB2 (73-155 aa). In yellow highlighted significantly enriched residues substitutions. (C) Amino acid substitutions enriched in the output in M9 succinate (selective media) when compared to the input for LIB3 (155-227 aa). In purple highlighted significantly enriched residues substitutions. (D) Amino acid substitutions enriched in the output in LB (nonselective media) when compared to the input for LIB1 (181 aa). (E) Amino acid substitutions enriched in the output in LB (nonselective media) when compared to the input for LIB2 (73-155 aa). In yellow highlighted significantly enriched residues substitutions. ( $F$ ) Amino acid substitutions enriched in the output in LB (nonselective media) when compared to the input for LIB3 (155-227 aa). (G) Heatmap summarizing panels A-F. For each residue, the Z-score of all detected substitutions was summed and represented. Higher values indicate strong enrichment as loss-of-function mutant in the given position. 
overlaps with a predicted carboxy-terminal Tudor domain in ProQ (Gonzalez et al. 2017), while none were selected in the upstream linker region (Fig. 2G). Overall, the distribution of all these enriched mutations supports the current coarse-grained structural model of ProQ as a protein with two distinguishable functional domains, separated by a variable linker region (Gonzalez et al. 2017).

To validate our screening results, we selected and individually introduced 13 of the highly enriched mutants in a ProO expression plasmid. All mutant proteins carried a car- boxy-terminal 3×FLAG epitope, added to ensure unbiased western blot detection and to permit immunoprecipitation with a generic $\alpha$-FLAG antibody. Following the introduction of these plasmids into Salmonella $\Delta$ proQ, we evaluated growth in M9-succinate, expecting they would phenocopy lack of ProQ (Fig. 3A,B). We found that four ProQ $_{\mathrm{F} 25 \mathrm{~S}}, \operatorname{ProQ}_{\mathrm{L71A}}, \operatorname{ProQ}_{\mathrm{R} 80 \mathrm{~A}}$, and ProQ $_{\mathrm{V} 96 \mathrm{D}}$ ) of the five tested mutations in the FinO domain did permit growth, whereas the ProQ ${ }_{\mathrm{Q} 118 \mathrm{R}}$ mutation still repressed growth under this nonpermissive condition (Fig. 3A). Mutation
A
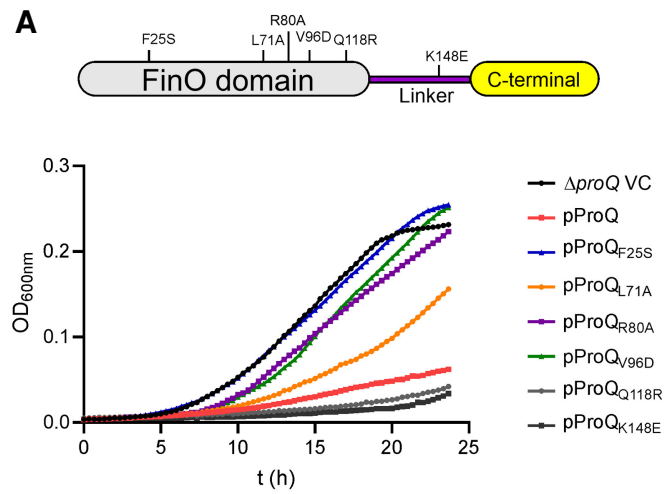

B
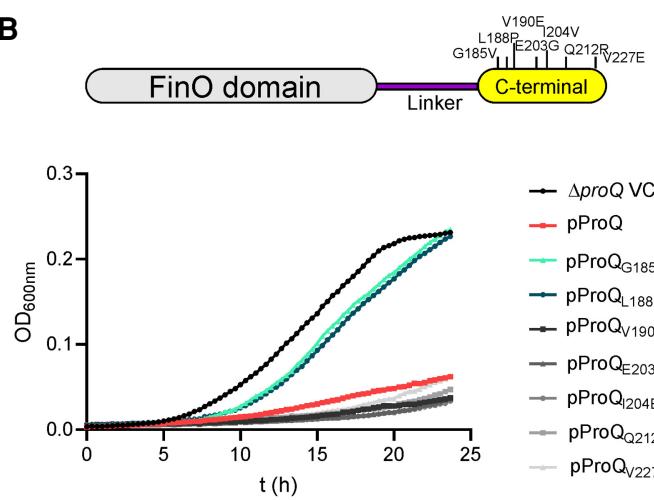

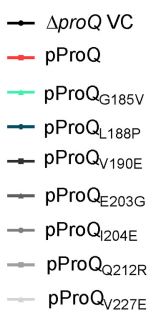

C

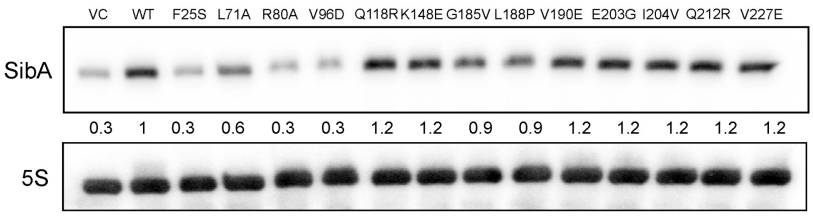

D

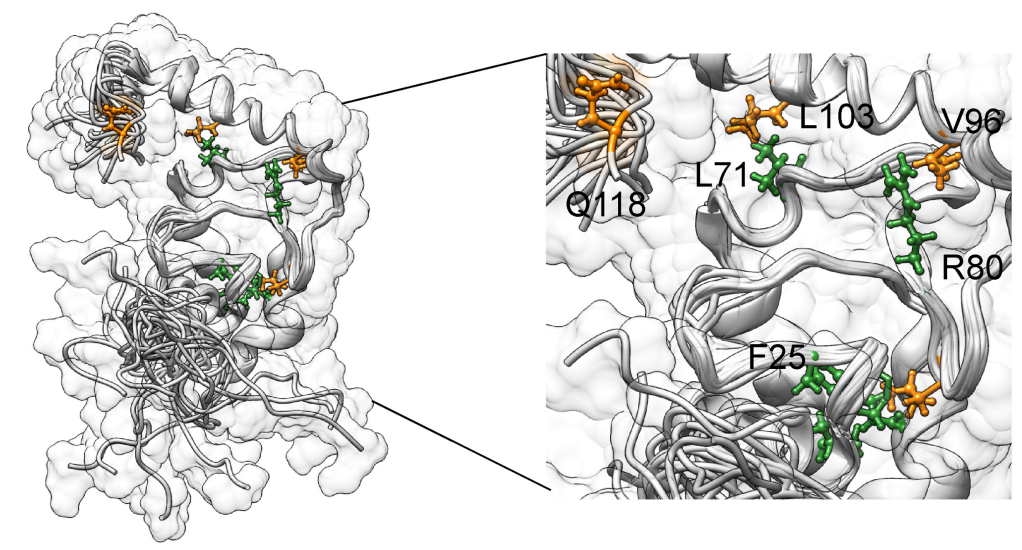

FIGURE 3. Identification of ProQ nonfunctional variants. (A) (Upper panel) Schematic representation of ProQ protein domains. Site-directed mu-

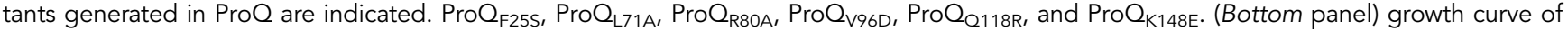
$\triangle p r o Q$ strain carrying either vector control (VC), pProQ WT protein or generated ProQ mutant variants indicated in the upper panel. Average values of three replicates are presented. (B) (Upper panel) Schematic representation of ProQ protein domains. Site-directed mutants generated

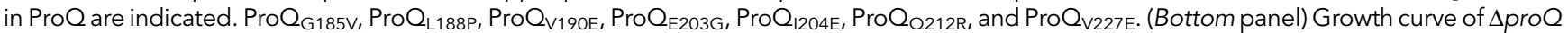
strain carrying either $\mathrm{VC}$ or the generated ProQ mutant variants indicated in the upper panel. Strains were inoculated to an $\mathrm{OD}_{600} \mathrm{~nm} 0.01$ and grown in a 96-well plate in $\mathrm{M9} 40 \mathrm{mM}$ succinate at $37^{\circ} \mathrm{C}$ for $24 \mathrm{~h}$ without shaking. Average values of three replicates are presented. (C) Northern blot detection of SibA expression in $\triangle p r o Q$ strain carrying pProQ WT or generated mutant variants as in $A$ and B. 5S RNA was detected as loading control. Quantification of relative SibA levels compared with the $\mathrm{pProQ}$ WT-carrying strain are indicated $(n=2)$. Total RNA samples were obtained from cultures grown in LB to $\mathrm{OD}_{600} \mathrm{~nm}$ 2.0. (D) Representation of ProQ NTD (FinO domain) (PDB ID: 5nb9). Residues enriched in deep mutational scanning are highlighted in green (LIB1) or orange (LIB2). On the right, highlighted cluster within ProQ structure of residues whose substitution render protein unstable, $\operatorname{ProQ}_{F 25 S}, \operatorname{Pro}_{R 80 A} \operatorname{ProQ}_{L 71 A}, \operatorname{Pro}_{V 96 D}$. 
Pro $_{K 148 E}$ in the linker region did not affect ProQ-mediated growth repression (Fig. 3A).

In regard to the carboxy-terminal domain, two (ProQ ${ }_{\mathrm{G} 185 \mathrm{~V}}$, ProO $_{\mathrm{L} 188 \mathrm{P}}$ ) of the seven tested point mutations passed this independent validation step, failing to repress growth in succinate (Fig. 3B). Of note, while all mutants in LIB3 were assumed to possess a wild-type FinO domain, we cannot rule out mutations in the FinO domain because the screen only involved sequencing of the mutagenized region of LIB3 (155-227). This possibility of additional mutations in other regions might explain the lower validation rate of carboxy-terminal point mutations. Nevertheless, our mutagenesis approach identified nonfunctional variants of ProQ via a single amino acid substitution in either the FinO domain or the carboxy-terminal domain.

\section{Effects of ProQ mutations on target RNA levels}

Assuming that ProQ primarily works as an RBP, we next tested whether the confirmed six mutations affected the ability of ProQ to interact with cellular RNA targets. We used the SibA sRNA as a proxy, which is a top ligand of ProQ in vivo (Smirnov et al. 2016; Holmqvist et al. 2018; El Mouali et al. 2021). Importantly, SibA must be strongly associated with ProO to be stable in the cell (Smirnov et al. 2016; Westermann et al. 2019), providing an easy readout for intact RNA recognition. Northern blot analysis revealed lower levels of SibA in the presence of mutants

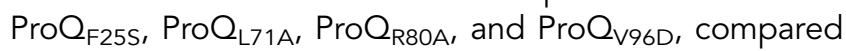
with the $\triangle$ proQ strain expressing wild-type ProQ; in fact, these mutants showed SibA levels close to the $\triangle$ proQ strain carrying the empty control vector (Fig. 3C). In other words, all four mutations that were unable to repress growth on succinate did not sustain normal SibA levels. Intriguingly, the $\operatorname{Pro}_{F 25 S}$, ProQ ${ }_{L 71 A}$, and $\operatorname{Pro}_{R 80 A}$ substitutions were also predicted to be crucial for RNA binding in the E. coli 3HB screen (Pandey et al. 2020), and these residues are in close vicinity to one another on the assumed RNA binding face of ProQ (Fig. 3D).

In contrast, the two confirmed carboxy-terminal mutants, ProQ ${ }_{\mathrm{G} 185 \mathrm{~V}}$ and $\mathrm{ProQ}_{\mathrm{L} 188 \mathrm{P} \text {, displayed minor differ- }}$ ences in SibA RNA levels when compared to the strain expressing wild-type ProQ, despite the loss-of-function in growth repression on succinate. These differences suggest that the FinO domain and the carboxy-terminal domain seem to play different roles in control of the succinate phenotype, with the amino-terminal mutations being more likely to generally impair ProO association with cellular target transcripts.

\section{RNA-binding deficient ProO proteins are unstable in vivo}

While the lower SibA levels might simply be explained by loss-of-function of key residues for RNA binding, we dou- ble-checked another possible cause, that is, reduced protein levels of these ProQ variants. After probing the expression levels of 13 of the mutant proteins on a western blot (Fig. 4A), we observed dramatically lower levels of the exact same four FinO domain mutants ProQ $_{F 25 S}$,

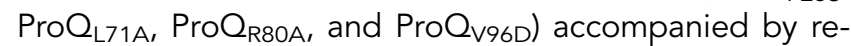
duced SibA levels and confirmation of the loss of growth suppression on succinate. In contrast, all other seven mutants showed at least wild-type protein levels, with the two carboxy-terminal mutants, $\operatorname{ProQ}_{\mathrm{G} 185 \mathrm{~V}}$ and $\mathrm{ProQ}_{\mathrm{L} 188 \mathrm{P} \text {, }}$ accumulating to even higher levels (Fig. 4A).

All the four mutations that caused reduced protein levels were located within the CDS of proQ and were therefore unlikely to impair ProO expression by affecting protein synthesis. To fully rule out general expression effects, we probed the mRNAs of the four constructs with FinO domain mutations on a northern blot. The mutant plasmids

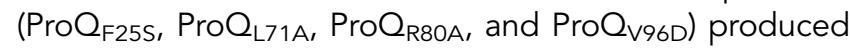
even more proQ mRNA than did the plasmid expressing wild-type ProQ suggesting an autogenous regulation of ProQ, where low levels of ProQ protein lead to an increase in proQ mRNA levels (Fig. 4B).

There were two possible explanations for the lower protein levels: impaired translation of the mutant mRNAs or decreased stability of the mutant proteins. Because the mutations were in the CDS, impaired translation was unlikely. Accordingly, we analyzed the rate of protein decay after stopping cellular translation with the antibiotic tetracycline as previously described (Gao et al. 2019). As shown in Figure $4 C$, the wild-type ProO protein is very stable in vivo, displaying almost no decay over the course of 120 min into the tetracycline treatment. In contrast, all four tested ProO mutant proteins ProO $_{\mathrm{F} 25 \mathrm{~S}}, \operatorname{ProO}_{\mathrm{L71A}}, \operatorname{ProO}_{\mathrm{R} 80 \mathrm{~A}}$, and Pro $_{\text {V96D }}$ ) display significantly reduced half-lives (Fig. 4C-E). Quantification of these western blot results revealed a dramatic decrease in protein half-life, from $>120$ min (WT ProQ) to $\sim 11 \mathrm{~min}$ for the Pro $_{\mathrm{R} 80 \mathrm{~A}}$ and Pro $\mathrm{Q}_{\mathrm{V} 96 \mathrm{D}}$ mutants, $\sim 5$ min for the Pro $_{F 25 s}$ mutant, and a milder reduction to $\sim 60 \mathrm{~min}$ for $\operatorname{ProQ}_{\mathrm{L71A}}$ (Fig. 4F). The reduced half-lives correlated well with the lower steady-state levels of these mutant proteins (see Fig. 4A). Our findings show that the mutations do not only impair RNA-binding, but also the intrinsic stability of the ProQ protein in vivo.

\section{Lon protease degrades ProO mutant proteins}

Protein turnover in enteric Gram-negative bacteria is primarily driven by members of the adenosine triphosphatase (ATPase) associated with cellular activities (AAA+) family. These proteases turn over functional proteins and also remove potentially toxic nonfunctional proteins (Gottesman and Maurizi 1992; Lee and Suzuki 2008; Gur et al. 2011). To determine which protease was responsible for clearing the nonfunctional ProQ proteins, we selected three major proteases from this family: ClpA, ClpX, and Lon. Probing 
A
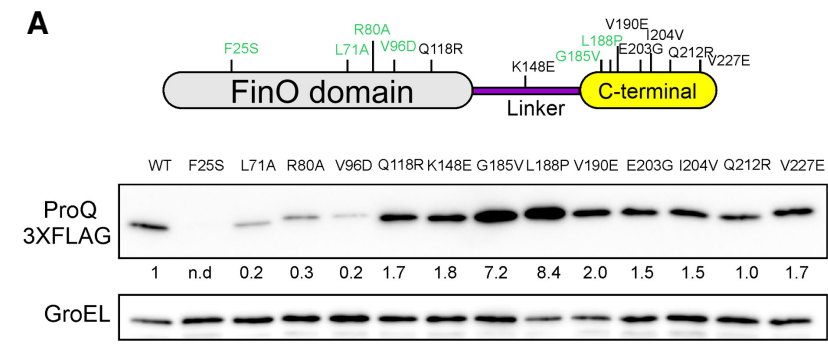

$\mathbf{B}$

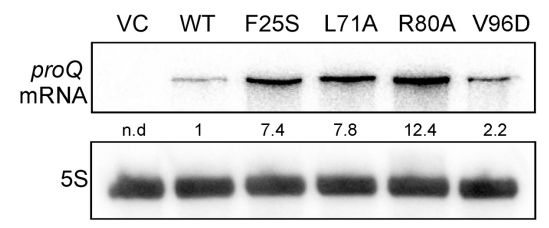

C

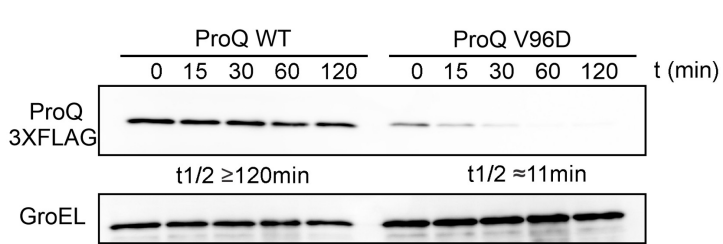

D

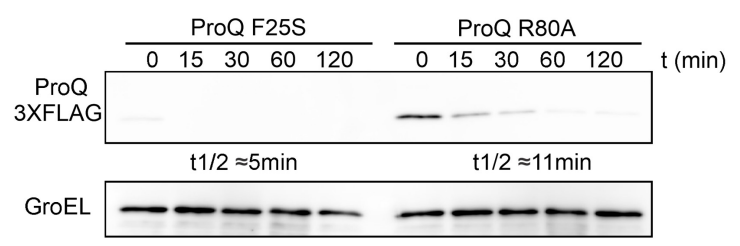

E

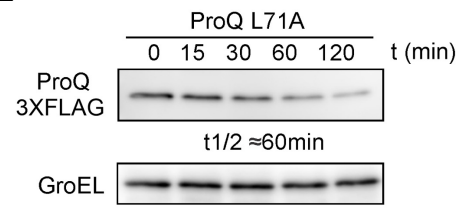

$\mathbf{F}$

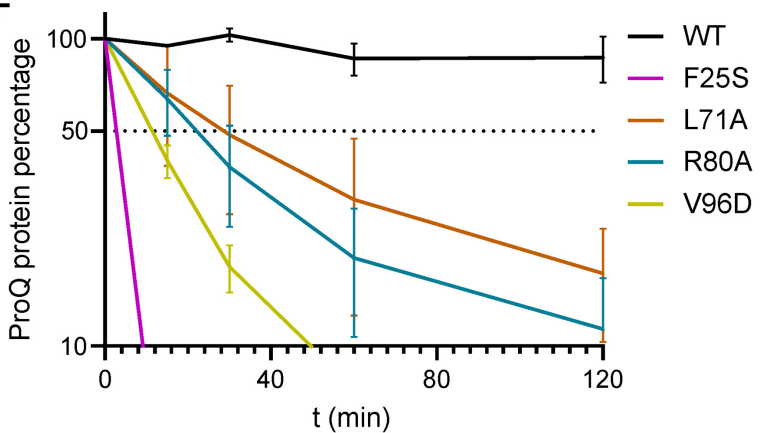

FIGURE 4. Mutations in the FinO domain render ProQ unstable. (A, upper panel) Schematic representation of ProQ protein domains. Sitedirected mutants generated in ProQ are indicated. In green, ProQ variants that are not functional. Pro $\mathrm{Q}_{\mathrm{F} 25 \mathrm{~S}}, \operatorname{Pro}_{\mathrm{L71A}}, \operatorname{Pro}_{\mathrm{R} 80 \mathrm{~A}}, \operatorname{ProQ}_{\mathrm{V} 96 \mathrm{D}}$, ProQ $_{G 185 V}$, and ProQ $L 188 \mathrm{P}$. (Bottom panel) Western blot of $\triangle$ proQ strain carrying either $\mathrm{pProQ}-3 \times \mathrm{FLAG}$ WT protein or generated ProQ mutant variants indicated in the upper panel. Quantification of band intensity of ProQ variants relative to ProQ expression in strain carrying pProQ$3 \times$ FLAG WT is shown $(n=2)$. GroEL was immunodetected as loading control. (B) Northern blot detection of proQ mRNA expression of pProQ

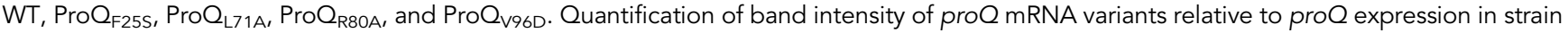
carrying pProQ-3 $\times$ FLAG WT is shown ( $n=2)$. 5S RNA was detected as loading control. In $A$ and $B$ samples were obtained from cultures grown in $L B$ to $O_{600} \mathrm{~nm}$ 2.0. (C) Protein stability assays of $\mathrm{pProQ} W T$ and $\operatorname{Pro}_{\mathrm{V} 96 \mathrm{D}}(n=2)$. (D) Protein stability assays of $\operatorname{Pro}_{\mathrm{F} 25 \mathrm{~s}}$, and $\operatorname{Pro}_{\mathrm{R} 80 \mathrm{~A}}(n=2)$. $(E)$ Protein stability assay of $\operatorname{ProQ}_{\mathrm{L71A}}(n=2)$. In $C-E$ cultures carrying the $\mathrm{ProQ}$ variants were grown in $\mathrm{LB}_{\mathrm{O}} \mathrm{OD}_{600 \mathrm{~nm}} 2.0$. To stop translation, tetracycline was added to a concentration of $50 \mu \mathrm{g} / \mathrm{mL}$. Samples for crude extracts were taken at time points $0,15,30,60$, and 120 min after tetracycline addition. ProQ-3×FLAG levels were determined by immunodetection. GroEL was detected as loading control. ( $F)$ Quantification of panels $C-E$.

for the $\operatorname{Pro}_{\mathrm{F} 255}, \operatorname{Pro}_{\mathrm{R} 80 \mathrm{~A}}$, and ProQ $\mathrm{V}_{\mathrm{V} 96 \mathrm{D}}$ mutant proteins in individual protease knockout strains of Salmonella, we observed full restoration to wild-type levels for all three mutant proteins in the $\Delta$ lon strain (Fig. 5A). In contrast, only minor changes were observed in the $\Delta c / p A$ or $\Delta c l p X$ strains (Fig. 5B,C).

The crucial involvement of Lon for removing nonfunctional ProQ proteins was corroborated by the results of the in vivo protein stability experiment. Specifically, we observed a dramatic increase in protein half-life for the ProO $_{F 25 S}$, ProO $_{R 80 A}$, and ProQ ${ }_{V 96 D}$ in the $\Delta$ lon strain (Fig. $5 \mathrm{D}-\mathrm{F})$, essentially restoring it to the wild-type situation $\left(t_{1 / 2}>120 \mathrm{~min}\right)$. These observations suggested a mechanism whereby ProQ variants unable to interact with RNA are actively targeted by the protease Lon and rapidly cleared from the cell.

\section{Evidence that ProO mutant proteins are defective in RNA-binding}

Our assumption that the selected FinO-domain mutants ProQ are defective in RNA binding was based on both, inference from an E. coli 3HB screen by others (Pandey et al. 2020) and the strong reduction of reduced SibA RNA levels observed here (Fig. 3C). The caveat being that these mutant proteins failed to accumulate in vivo (Fig. 4A), which limited conclusions regarding intracellular activity. In this regard, the $\Delta$ lon strain provided a unique opportunity to prove their inability to bind target RNAs in vivo. Indeed, northern blot analysis showed that despite the increase in ProO protein levels, SibA RNA levels remained low in the $\Delta$ lon strain, as compared to Lon-proficient Salmonella (Fig. 6A). In other words, these FinO-domain 
A

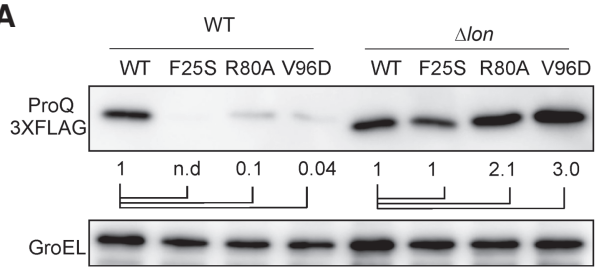

B

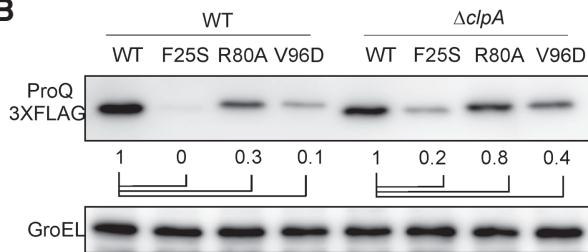

C

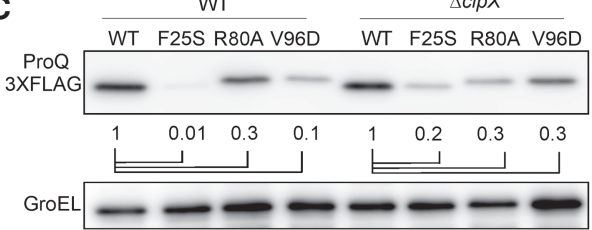

D

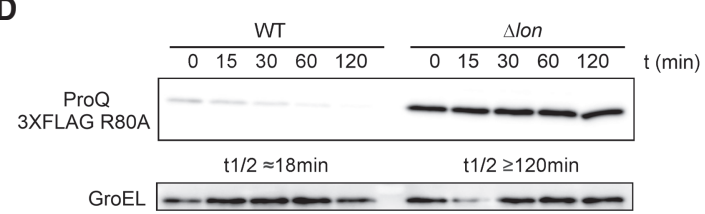

E

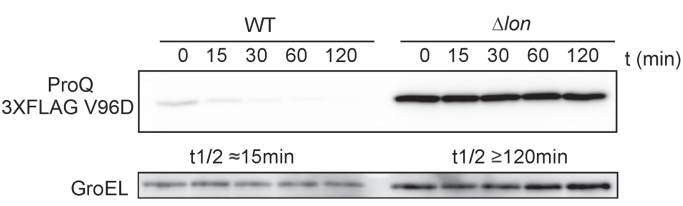

F

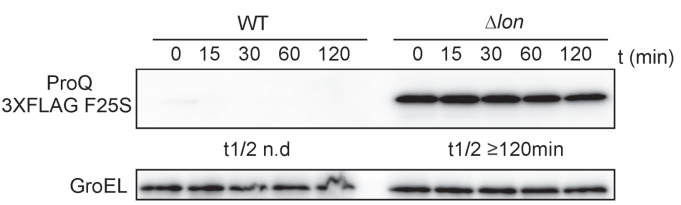

FIGURE 5. ProQ inability to interact with RNA leads to Lon-mediated proteolysis. Immunodetection of ProQ-3 $\times F L A G$ variants $p$ ProQ WT, ProQ ${ }_{V 96 \mathrm{D}}, \operatorname{ProQ}_{\mathrm{F} 25 \mathrm{~S}}$, and $\mathrm{ProQ}_{\mathrm{R} 80 \mathrm{~A}}$ in $(A) \mathrm{WT}$ and $\Delta$ lon (upper panel) (B) WT and $\Delta c l p A$ (middle panel) (C) WT and $\Delta c / p X$ (bottom panel). GroEL was detected as loading control $(n=2)$. Quantification of band intensity of ProQ variants relative to ProQ expression in strain carrying pProQ-3 $\times F L A G ~ W T$ is indicated for each genetic background WT, $\Delta /$ on, $\Delta c l p A$, and $\Delta c l p X$. Absence of Lon but not ClpA or ClpX affects steady state levels of ProQ $\mathrm{V}_{96 \mathrm{D}}, \operatorname{ProQ}_{\mathrm{F} 25 \mathrm{~S}}$, and $\mathrm{ProQ}_{\mathrm{R} 80 \mathrm{~A}}$ when compared to $\mathrm{pProQ}$ WT. Protein stability assays in WT and $\Delta$ lon of (D) pProQ WT and

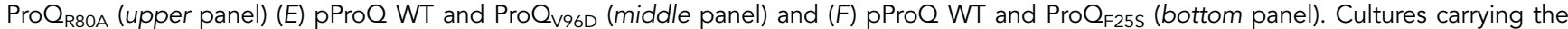
ProQ variants were grown in $\mathrm{LB}$ to $\mathrm{OD}_{600 \mathrm{~nm}}$ 2.0. To stop translation, tetracycline was added to a concentration of $50 \mu \mathrm{g} / \mathrm{mL}$. Samples for crude extracts were taken at time points $0,15,30,60$, and $120 \mathrm{~min}$ after tetracycline addition. ProQ-3×FLAG levels were determined by immunodetection. GroEL was detected as loading control $(n=2)$.

mutants could not stabilize the SibA RNA target even when present at wild-type concentration.

In order to prove loss of RNA binding more directly, we selected the ProQ $_{R 80 A}$ mutant for RNA coimmunoprecipitation (colP) in vivo. As shown in Figure 6B, colP with the wild-type ProO protein recovered with an $\alpha$-FLAG antibody strongly enriched the SibA RNA, whereas no enrichment was observed with the mutant protein. Next, we globally analyzed the transcripts from the eluate fractions by RNA-seq. Precipitation with wild-type ProO recovered the expected suite of dominant ProQ-associated sRNAs, for example, SibA, SibD, SibC, and SraL (Fig. 6C); in other words, the plasmid-expressed ProQ protein showed the same target profile as in previous colP studies with ProO expressed from the chromosome (Smirnov et al. 2016; El Mouali et al. 2021). In contrast, $\operatorname{Pro}_{R 80 A}$ had a more restricted target suite than wild-type ProO, and enriched entirely different transcripts (Fig. 6D). In fact, ProQ ${ }_{R 80 A}$ associates nonspecifically with abundant mRNAs of ribosomal proteins, flagella components and even its own messenger (Fig. 6C,D; Supplemental Fig. S3A). A clustering analysis revealed that the RNA profile of $\mathrm{ProQ}_{R 80 A}$ overall is similar to the colP with the empty vector control (Supplemental Fig. S3B). Thus, the R80A substitution ren- ders ProQ unable to bind ProQ dependent RNAs, a deficiency that is associated with rapid degradation by the Lon protease.

\section{$\mathrm{Hfq}$ is also targeted by Lon}

ProQ is one of two major RBPs to facilitate sRNA activity in Salmonella, the other being the hexameric Sm-like protein, Hfq (Holmqvist et al. 2016, 2018). Assembled Hfq hexamers interact with RNA through three different RNAbinding surfaces: their proximal and their distal face, and the rim. Residue substitutions rendering $E$. coli $\mathrm{Hfq}$ unable to interact with a subset of RNA species have been reported for each of these three surface regions (Mikulecky et al. 2004; Hankins et al. 2010; Panja and Woodson 2012; Sauer et al. 2012; Panja et al. 2015; Schu et al. 2015). Intriguingly, some of these mutant proteins, for example, $\mathrm{Hfq}_{\mathrm{D} 40 \mathrm{~A}}$ and $\mathrm{Hfq}_{\text {Y55A, }}$ also exhibited reduced protein levels in E. coli (Zhang et al. 2013). Here, when we generated the corresponding mutations in $\mathrm{Hfq}$ from Salmonella expressed from a plasmid, we also observed a reduction in protein expression of $\mathrm{Hfq}_{\mathrm{D} 40 \mathrm{~A}}$ and $\mathrm{Hfq}_{\mathrm{Y} 55 \mathrm{~A}}$ as compared to wild-type $\mathrm{Hfq}$ (Fig. 7A). As a control, we generated the distal face mutant $\mathrm{Hfq}_{\mathrm{Y} 25 \mathrm{D}}$ which accumulated to wild-type $\mathrm{Hfq}$ levels 
A

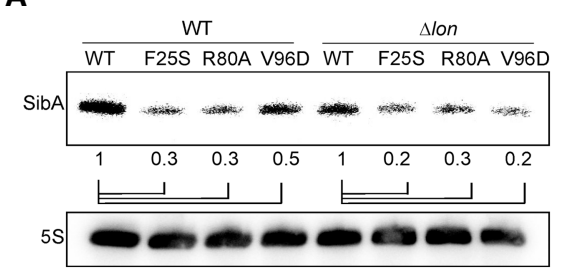

B

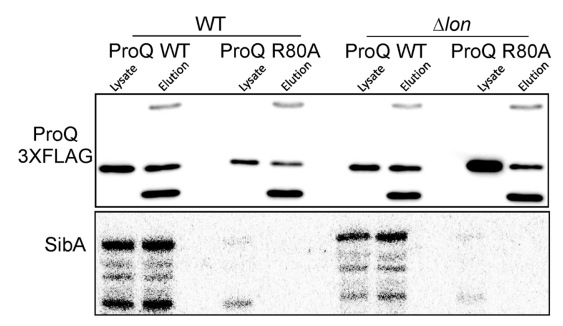

C

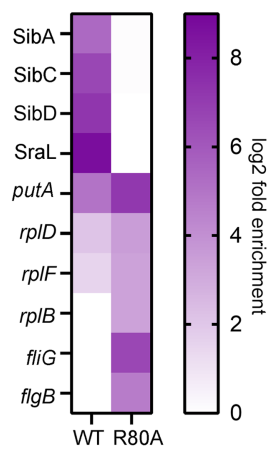

D

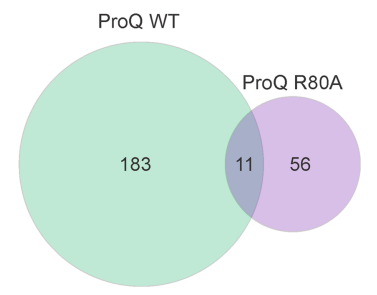

FIGURE 6. ProQ nonfunctional variants are unable to interact with RNA. (A) Northern blot detection of SibA sRNA expression in $\triangle$ proQ background expressing PProQ variants: $\mathrm{PProQ}$ WT, ProQ $_{F 25 S}$, ProQ $_{R 80 A}$, and ProQ ${ }_{\text {V96D }}$ in WT (left) and $\Delta$ lon (right) deletion background. 5S RNA was detected as loading control. Samples were obtained from cultures grown in LB to $\mathrm{OD}_{600 \mathrm{~nm}}$ 2.0. Quantification of relative SibA levels compared with the pProQ WT-carrying strain in both WT and $\Delta$ lon background are indicated $(n=2)$. (B) Immunoprecipitation of pProO WT and ProQ $\mathrm{R} 80 \mathrm{~A}_{\text {in }} \mathrm{WT}$ (left) and $\Delta$ lon (right) mutant background, lysate and elution extracts of protein (upper panel) and RNA (bottom panel) were prepared. Immunodetection (upper panel) of PProO WT and ProQ $_{R 80 A}$ protein variants immunoprecipitated. Northern blot detection (bottom panel) of coimmunoprecipitated SibA sRNA $(n=2)$. (C) Heatmap of highly enriched transcripts in RIP-seq of pProO WT and ProQ ${ }_{R 80 A}$. (D) Venn diagram of significantly enriched transcripts ( $\log _{2}$ fold $\geq 2.0 ; P$-adj $\leq 0.05$ ) in $\mathrm{pProQ} W T$ and $\operatorname{ProQ}_{R 80 \mathrm{~A}}$ in $\Delta$ lon background compared to VC strain.

(Fig. 7A), as previously reported in E. coli (Zhang et al. 2013).

To test a potential role of Lon in quality control of RNAbinding deficient $\mathrm{Hfq}$ variants, we selected the HfqY55A mutant for stability analysis. Similar to ProQ, wild-type Hfq displayed a half-life of $\geq 120$ min in our tetracycline treatment assay, whereas the intracellular half-life of the $\mathrm{Hfq}_{\text {Y55A }}$ protein was much shorter (Fig. 7B). Moreover, we observed for the Hfqy55A protein the same clear rescue of intracellular stability in the $\Delta$ lon mutant (Fig. 7C) as we had with the RNA-binding deficient ProO mutants above. Wild-type Hfq was stable over the course of $120 \mathrm{~min}$, and an additional increase in $\mathrm{Hfq}$ protein levels was observed in the $\Delta$ lon mutant (Fig. 7D).

The Hfqy55A variant is impaired in hexamer formation, which requires interaction with RNA (Panja and Woodson 2012; Zhang et al. 2013; Basu et al. 2021). We hypothesized that the reduced intracellular stability of Hfqr55A was due to the inability of this mutant protein to form the active hexamer. Interestingly, it has been shown that wild-type $\mathrm{Hfq}$ monomers can form heterohexamers with $\mathrm{Hfq}$ mutant variants, and thereby rescue interaction with RNA in E. coli (Panja and Woodson 2012; Basu et al.
2021). Mimicking this approach, we expressed HfqY55A in a Salmonella $h f q+$ background, expecting that heterohexamers would form and lead to stabilization of the mutant protein. We used the $3 \times$ FLAG tag on the mutant protein for selective detection by western blot. We discovered that the half-life of the mutant $\mathrm{Hfq}_{\mathrm{Y} 55 \mathrm{~A}}$ protein dramatically increased to $\geq 120 \mathrm{~min}$, making it indistinguishable from wild-type $\mathrm{Hfq}$, regardless of the presence or absence of Lon (Fig. 7E,F).

\section{DISCUSSION}

The global and specialized roles played by RBPs of the ProQ/FinO family reflect post-transcriptional control mechanisms that have been discovered recently in a number of bacteria, including E. coli, Legionella pneumophila, Neisseria meningitidis, and S. enterica (Attaiech et al. 2016; Smirnov et al. 2016; Holmqvist et al. 2018; Bauriedl et al. 2020; Gerovac et al. 2020; Melamed et al. 2020; El Mouali et al. 2021). Although it was originally proposed that ProO only functioned as a positive regulator of proline transport (Milner and Wood 1989), it was subsequently discovered that this RNA chaperone targeted a large number of cellular transcripts (Smirnov et al. 2016). It has been inferred from a combination of protein conservation, biochemical and genetic studies that the key regulatory function of ProQ is associated with the FinO domain and not the variable carboxy-terminal region. However, this assumption needed to be tested experimentally. Our present study pioneers a saturating mutagenesis screen over the entire length of ProQ under physiological conditions. We selected mutations that inactivate ProQ, based on the ability of the RBP to repress microaerobic growth of Salmonella on succinate.

One unexpected finding from our screen was that certain residues in the variable carboxyl terminus are required for ProO function. We identified two validated carboxyterminal mutations, a change of glutamine 185 to valine, and leucine 188 to proline, that lie in a region which has been predicted to be involved in RNA binding by a protein structure modeling approach (Gonzalez et al. 2017). However, these mutations only had a modest influence on SibA RNA, a sensitive reporter of ProQ activity (Fig. $3 C)$, resembling the impact of frameshift mutations in the carboxy-terminal domain of the related RocC protein in Legionella which also impaired regulation of RocC targets 
A

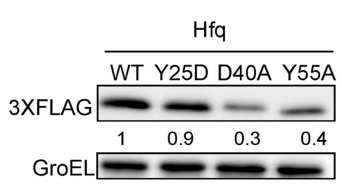

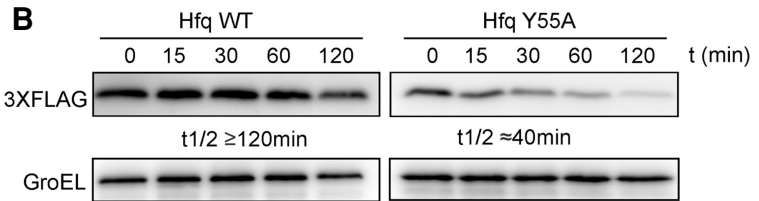

C

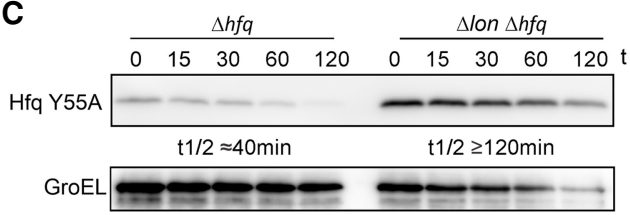

$\mathbf{E}$

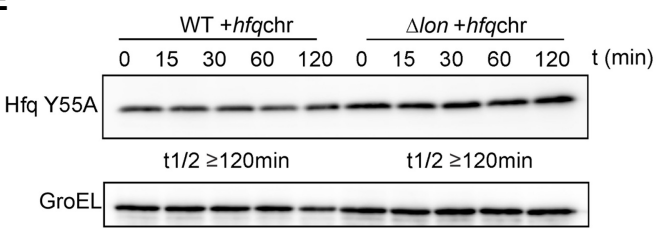

D

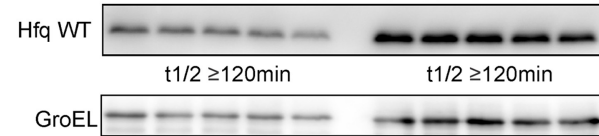

$\mathbf{F}$

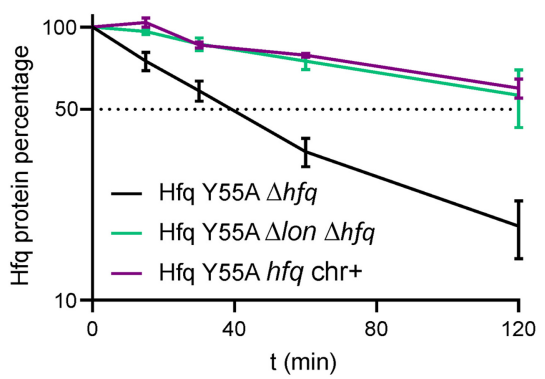

FIGURE 7. Lon targets the RBP Hfq. (A) Immunodetection of Hfq-3×FLAG variants pHfqwT, HfqY25D, HfqD40A, and Hfqy55A. Quantification of band intensity of $\mathrm{Hfq}$ variants relative to $\mathrm{Hfq}$ expression in strain carrying $\mathrm{pHfq}-3 \times \mathrm{FLAG} \mathrm{WT}$ is indicated $(n=2)$. GroEL was detected as loading control. (B) Protein stability assays of pHfqwT and Hfq $\mathrm{Y}_{55 \mathrm{~A}}$ in a $\Delta h f q$ background $(n=2)$. (C) Protein stability assays in $\Delta h f q$ and $\Delta h f q \Delta / o n$ backgrounds of HfqY55A $(n=2)$. (D) Protein stability assays in $\Delta h f q$ and $\Delta h f_{q} \Delta$ lon backgrounds of HfqWT $(n=2)$. (E) Protein stability assays in WT and $\Delta$ lon backgrounds of $\mathrm{Hfq}_{555 \mathrm{~A}}(n=2)$. $(F)$ Quantification of panels $C$ and $E$. In $B-E$ cultures carrying the $\mathrm{Hfq}_{\mathrm{fariants}}$ were grown in $\mathrm{LB}$ to $\mathrm{OD}_{600}$ $\mathrm{nm}$ 2.0. To stop translation, tetracycline was added to a concentration of $50 \mu \mathrm{g} / \mathrm{mL}$. Samples for crude extracts were taken at time points 0,15 , 30, 60, and $120 \mathrm{~min}$ after tetracycline addition. Hfq-3×FLAG levels were determined by immunodetection. GroEL was detected as loading control.

without affecting RNA-protein interactions (Attaiech et al. 2016).

Until now, the evidence for an independent role for the ProQ CTD was circumstantial as some RNA targets of $E$. coli ProQ are bound more efficiently by the full-length protein than by the NTD alone (Stein et al. 2020). To improve our understanding of the carboxy-terminal domain, we suggest that other loss-of-function approaches should be used in future. An obvious selectable phenotype would be resistance to 3,4-dehydroproline, which was the first indication of the physiological role of ProQ (Stalmach et al. 1983; Milner and Wood 1989). If the same carboxy-terminal residues played a functional role that involved a different aspect of ProO activity, it would strengthen the idea that the carboxyl terminus constitutes an important domain in its own right.

As well as revealing an unexpected function for the CTD, our scanning mutagenesis over the full-length protein emphasizes the importance of the amino-terminal FinO domain for ProQ function in vivo. The screen predicts 27 residue substitutions within this domain that lead to a nonfunctional ProQ variant, consistent with the 25 residue substitutions reported in the recently published three-hybrid (3HB) based screen, which used E. coli ProQ or its NTD and cspE or SibB RNAs as a molecular bait (Pandey et al.
2020). While most of the described amino acid substitutions had overlapping functions for both cspE and SibB, some specificity was observed (e.g., $\operatorname{ProQ}_{\mathrm{K} 35 \mathrm{E}}$ and Pro $\mathrm{Q}_{\text {R2OP }}$ only influenced SibB binding).

Overall, a strong overlap between the mutations we identified in the Salmonella ProQ NTD with the mutations from the E. coli $3 \mathrm{HB}$ screen was observed. Key differences include E. coli Pro $\mathrm{Q}_{\mathrm{K} 35 \mathrm{E}}$, a mutation that was not enriched in the Salmonella library, and our Salmonella ProQ ${ }_{\text {V96D }}$ mutant, which was not detected in the E. coli screen (Supplemental Fig. S4; Supplemental Table S2). These observations indicate subtle differences between the RNAbinding faces of the E. coli and Salmonella ProQ proteins, despite the high level of similarity between these proteins.

The AAA+ protease Lon plays a crucial role in enteric bacteria by degrading important proteins to optimize particular regulatory functions (Gottesman and Maurizi 1992; Gottesman 1996; Lee and Suzuki 2008). However, Lon is not the major degradation enzyme of ProQ, as wild-type ProO does not accumulate to higher levels in the absence of Lon (Fig. 5A). Importantly, we have discovered several amino acid substitutions in the FinO domain that both abrogate RNA binding and to the resulting mutant ProO proteins being rapidly degraded by Lon. This finding is consistent with a quality control mechanism of ProO 
function in vivo that actively targets ProO molecules that fail to associate with RNA (Fig. 8).

To support our suggestion that Lon-mediated proteolysis is a general mechanism that prevents the accumulation of nonfunctional RBPs in bacteria, we show that Lon is also responsible for degrading an RNA-binding deficient variant of the sRNA chaperone Hfq. Furthermore, the Narberhaus laboratory recently showed that the Ffh protein component of the conserved signal recognition particle (SRP) is also targeted by Lon in the absence of binding with its major ligand, the 4.5S RNA (Sauerbrei et al. 2020). Collectively, these observations suggest that in vitro systems should be developed to prove directly whether the proposed Lon-mediated degradation of these RBPs is indeed dependent upon RNA-binding. While it is unclear at this stage whether Salmonella ProO can be degraded by purified Lon protease, we note that the Hfq protein of Pseudomonas aeruginosa may be a useful experimental tool as it is easily degraded by Lon in vitro (Fernandez et al. 2016).

Lon is an important protease in bacteria that plays a central role in maintaining cellular protein homeostasis by removing misfolded proteins (Simon et al. 1979; Chung and Goldberg 1981) and controls the turnover of important regulatory proteins including $\mathrm{H}-\mathrm{NS}$, RcsA, SoxS, and SulA (Schoemaker et al. 1984; Torres-Cabassa and Gottesman 1987; Shah and Wolf 2006; Choi and Groisman 2020). The accumulated knowledge about the many functions of Lon in the cell raises the possibility that Lon-mediated degradation of RBPs could be regulated by additional factors.

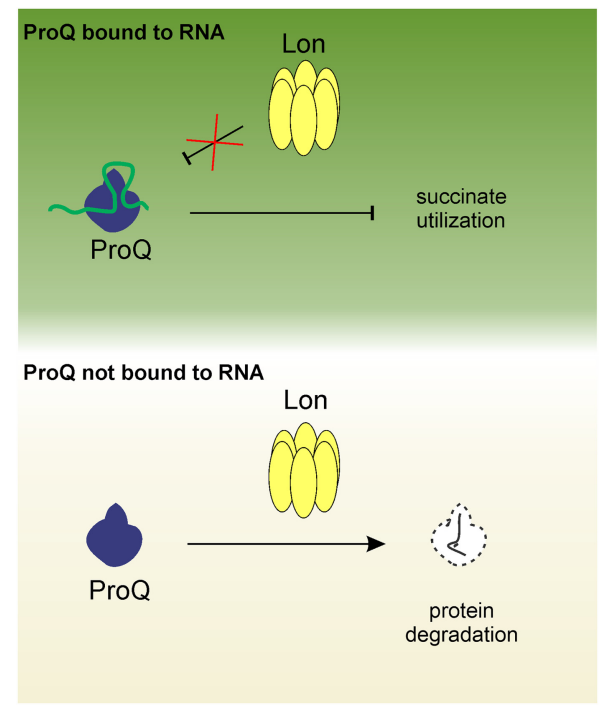

FIGURE 8. Role of Lon-mediated quality control of ProQ. When interacting with RNA, ProQ is stable as it escapes Lon-mediated degradation and carries out its in vivo function as suppressor of succinate utilization in Salmonella (upperpanel). In the absence of RNA binding, however, ProQ is unstable as it is actively targeted by Lon (bottom panel).
For example, cleavage of H-NS by Lon only occurs in the absence of bound DNA (Choi and Groisman 2020). Furthermore, the bacterial toxin CcdA, which is part of a plasmid-borne toxin-antitoxin system, is only degraded by Lon when not bound to the antitoxin (Van Melderen et al. 1994, 1996; Van Dijl et al. 1998; Lee and Suzuki 2008). This would fit with our prediction that Lon degrades $\mathrm{Hfq}$ when the initial monomeric protein has not yet assembled into the active hexamer.

Our experimental evolution strategy was based upon the Salmonella succinate-related phenotype, which holds great promise for the design of additional genetic screens to search for novel factors that modulate the activity of Lon and ProQ, either alone or in combination.

\section{MATERIALS AND METHODS}

\section{Bacterial strains and growth conditions}

The bacterial strains and plasmids used in this study are listed in Supplemental Table S1. Salmonella enterica serovar Typhimurium SL1344 (Hoiseth and Stocker 1981) and derivative strains were cultivated in Lysogeny broth (LB) (tryptone $10 \mathrm{~g} / \mathrm{L}$, yeast extract $5 \mathrm{~g} / \mathrm{L}$, and sodium chloride $10 \mathrm{~g} / \mathrm{L}$ ) or mineral medium $\mathrm{M} 9$. Mineral M9 contained: (i) $12.8 \mathrm{~g} / \mathrm{L} \mathrm{Na}_{2} \mathrm{HPO}_{4} \times 7 \mathrm{H}_{2} \mathrm{O}, 3 \mathrm{~g} / \mathrm{L} \mathrm{KH}_{2}$ $\mathrm{PO}_{4}, 0.5 \mathrm{~g} / \mathrm{L} \mathrm{NaCL}, 1 \mathrm{~g} / \mathrm{L} \mathrm{NH}_{4} \mathrm{Cl}, 2 \mathrm{mM} \mathrm{MgSO}$, $0.1 \mathrm{mM} \mathrm{CaCl}$, $0.0004 \%$ Histidine, $0.5 \mu \mathrm{g} / \mathrm{mL}$ Thiamine; (ii) trace elements: 134 $\mu \mathrm{M}$ EDTA, $31 \mu \mathrm{M} \mathrm{FeCl}_{3} \times 6 \mathrm{H}_{2} \mathrm{O}, 6.2 \mu \mathrm{M} \mathrm{ZnCl}_{2}, 0.76 \mu \mathrm{M} \mathrm{CuCl}_{2}$ $\times 2 \mathrm{H}_{2} \mathrm{O}, 0.42 \mu \mathrm{M} \mathrm{CoCl} 2 \times 2 \mathrm{H}_{2} \mathrm{O}, 1.62 \mu \mathrm{M} \mathrm{H} \mathrm{BO}_{3}, 81 \mathrm{nM}$ $\mathrm{MnCl}_{2} \times 4 \mathrm{H}_{2} \mathrm{O}$; and (iii) supplemented with $40 \mathrm{mM} \mathrm{Na}$-succinate (Sigma-Aldrich) as the carbon source. Bacterial cultures were inoculated to an $\mathrm{OD}_{600 \mathrm{~nm}} 0.01$ and incubated at $37^{\circ} \mathrm{C}$ without aeration for microaerobic conditions, as previously described (Serna et al. 2010; Rosenberg et al. 2021), or with 200 rpm shaking for aerobic conditions. For solid growth, Salmonella strains were streaked on LB or M9 Agar supplemented with 40 mM Na-succinate as the sole carbon source.

Growth curves were carried out in 96-well plates in a final volume of $200 \mu \mathrm{L}$. Plates were inoculated to an $\mathrm{OD}_{600 \mathrm{~nm}} 0.01$ with cell suspensions of the strains of interest prewashed in $1 \times$ PBS. Plates were incubated at $37^{\circ} \mathrm{C}$ without shaking for $24 \mathrm{~h}$ in a Tecan Infinite M Plex plate reader. Growth rate was assessed by turbidity measurement (OD $600 \mathrm{~nm}$ ) every $15 \mathrm{~min}$.

\section{Genetic manipulations and site-directed mutagenesis}

Salmonella enterica deletion strains were generated by standard gene replacement as previously described (Datsenko and Wanner 2000). The generated PCR fragment is transformed in competent Salmonella as for deletion strains (Datsenko and Wanner 2000). When required, the antibiotic cassette was removed by the expression of Flp recombinase from pCP20 as previously described (Cherepanov and Wackernagel 1995).

A proQ and proQ-3×FLAG variant was cloned in between Aatll/ $\mathrm{Xbal}$ in pZE12luc backbone, to be expressed under proO native promoter with oligonucleotide pairs JVO-16806/JVO-8524 and 
JVO-16806/JVO-12604, respectively. The resulting expression plasmid pProQ-3×FLAG was used as a template for generation of ProQ point mutation variants. The mutations were generated by site-directed mutagenesis. Primers of $40 \mathrm{bp}$ that contain the substitution of interest were used to amplify by PCR pProQ- $3 \times$ FLAG. The following mutations were generated with the indicated oligonucleotides pairs: ProQ $_{\text {F25S }}$ (JVO18952/JVO18953), $\operatorname{ProQ}_{R 80 A}$ (JVO18550/JVO18551), ProQ L71A (JVO18552/JVO18553), ProQ V96D $_{\text {(JVO18954/JVO18955), ProQ }}$ Q118R $_{\text {(JVO18956/JVO1 }}$ 6957), $\operatorname{ProQ}_{K 148 E}(J V O 18960 / J V O 18961), \operatorname{ProQ}_{L 188 P}$ (JVO189 62/JVO18963), ProQ ${ }_{V 190 E}(J V O 18964 / J V O 18965), P_{0212 R}$ (JVO18966/JVO18967), ProQ V227E (JVO18968/JVO18969), ProQ $_{\mathrm{G} 185 V}(J V O 19480 / J V O 19481), \operatorname{ProQ}_{1204 V}(J V O 19482 / J V O 1$ 9483), ProQ $_{E 203 G}(J V O 19484 / J V O 19485)$. The resulting reaction was Dpnl-treated and transformed into chemo competent $E$. coli TopF. Mutant candidates were validated by Sanger sequencing.

Similarly, an hfq-3×FLAG variant was cloned between Xhol/ Xbal in pZE12luc backbone to be expressed under hfq native promoter with oligonucleotide pairs JVO19817/JVO19818. The resulting expression plasmid pHfq $3 \times \mathrm{FLAG}$ was used as a template to generate $\mathrm{Hfq}$ point mutation variants as described above for ProQ. Oligonucleotides used for strains construction, cloning and site-directed mutagenesis are listed in Supplemental Table S1.

\section{Protein crude extracts and western blot}

Bacterial cultures were grown to $\mathrm{OD}_{600 \mathrm{~nm}}$ 2.0. A volume of cells that represents $0.2 \mathrm{OD}_{600 \mathrm{~nm}}$ were pelleted and resuspended in $200 \mu \mathrm{L}$ of $1 \times$ Laemmli buffer. Samples were stored at $-20^{\circ} \mathrm{C}$. Protein extracts were subjected to SDS-PAGE separation and transferred to a PVDF filter membrane. The membrane was subjected to immunodetection of $3 \times F L A G$ tagged proteins by using as primary antibodies, monoclonal anti-FLAG M2 (Sigma-Aldrich \#F1804) 1:2000 for both ProQ-3×FLAG and Hfq-3×FLAG detection. As loading control, GroEL was detected with anti-GroEL (Sigma-Aldrich, \#G6532). As secondary antibodies, anti-mouse (Thermo Fisher, cat\# 31430) and anti-rabbit (Thermo Fisher, cat\# 31460) conjugated to horseradish peroxidase were used for anti-FLAG and anti-GroEL, respectively. For detection, ECL Prime Western Blotting Detection Reagent (Cyvita) served as a substrate. All western blot experiments were performed at least twice.

\section{In vivo protein stability assays}

Bacterial cultures were grown to $\mathrm{OD}_{600 \mathrm{~nm}}$ 2.0. To stop translation, tetracycline was added to the culture to a concentration of $50 \mu \mathrm{g} /$ $\mathrm{mL}$ as previously described (Gao et al. 2019). Time points were collected, prior to the addition of the antibiotic, t0, and after $15,30,60,120 \mathrm{~min}$. For each time point, $96 \mu \mathrm{L}$ of culture were mixed with $24 \mu \mathrm{L}$ of $5 \times$ Laemmli buffer. Samples were stored at $-20^{\circ} \mathrm{C}$. The levels of ProQ-3×FLAG WT, Hfq-3xFLAG WT and mutant variants were determined by immunodetection by western blot as described above. All protein stability assays were performed in duplicate, the band intensity of ProQ-3×FLAG variants and $\mathrm{Hfq}-3 \times \mathrm{FLAG}$ variants was quantified, and the relative half-life $t_{1 / 2}$ at which there is a $50 \%$ decrease in band intensity is indicated for each protein stability assay.

\section{Total RNA isolation and northern blot}

Bacterial cultures were grown to $\mathrm{OD}_{600 \mathrm{~nm}} 2.0$, a volume of cells that represents $4 \mathrm{OD}_{600 \mathrm{~nm}}$ was collected, and total RNA extracted by the hot phenol method followed by a DNase I treatment. Samples of $10 \mu \mathrm{g}$ of DNAse-treated total RNA were subjected to electrophoretic separation in Tris-Borate-EDTA (TBE) $6 \%$ acrylamide gels containing $8.3 \mathrm{M}$ urea. RNAs were transferred to Hybond N+ (GE Healthcare) filters and transcripts of interest (SibA sRNA and proQ mRNA) were detected by hybridization with $5^{\prime}$ radiolabeled oligonucleotides as probes. A minimum of two biological replicates for each northern blot were carried out. For oligonucleotides labeling, in a $20 \mu \mathrm{L}$ reaction, $10 \mathrm{pmol}$ of the oligonucleotides used as probes were $5^{\prime}$-labeled with $10 \mu \mathrm{Ci}$ of ${ }^{32} \mathrm{P}-\gamma$-ATP by PNK (T4 polynucleotide kinase, Thermo Fisher Scientific) for $1 \mathrm{~h}$ at $37^{\circ} \mathrm{C}$. Labeled oligonucleotides were further purified via Microspin G-25 columns (GE Healthcare) to remove unincorporated ${ }^{32} \mathrm{P}-\gamma$-ATP. The radioactive signal was imaged with the Typhoon FLA 7000 (GE Healthcare). Oligonucleotides used as probes are listed in Supplemental Table S1.

\section{Deep mutational scanning and DNA library preparation}

Libraries of ProQ mutants were generated by using GeneMorph II EZClone Domain Mutagenesis Kit (Agilent). As a template, three different overlapping libraries were generated, LIB1 (1-81 aa), LIB2 (73-155 aa), and LIB3 (155-227 aa). First, a PCR template was generated for each library by amplifying overlapping regions of the proQ ORF with JVO16789/JVO16809, JVO16810/ JVO16728, and JVO16811/JVO16790 for LIB1, LIB2, and LIB3, respectively, generating 240, 250, and 218 base pair PCR templates. For each library, a PCR fragment was generated by error prone PCR following Agilent guidelines for the low mutation rate (0-4.5 mutations/kB) (Supplemental Fig. S2). The purified PCR products were subsequently used as megaprimers to generate the library of mutants in the plasmid pZE-ProQ-3×FLAG by following GeneMorph II EZClone Domain Mutagenesis Kit (Agilent) guidelines. For each library, around 5000 colonies were obtained upon transformation of Dpnl-treated mutagenesis reaction into chemo competent E. coli TopF cells. All transformants were pooled, and the mutant plasmid library was extracted by plasmid Midi prep (Qiagen) and transformed by electroporation into $\triangle$ proQ cells.

Around 30,000 transformants/library were obtained and pooled in $10 \mathrm{~mL} 1 \times \mathrm{PBS}$. Cells were washed twice on fresh $1 \times$ PBS prior to inoculation on the selective (M9+succinate) and nonselective (LB) media. The turbidity of the transformants suspension was measured and 4 ODs were stored as "input." Next, 2 ODs were inoculated in $50 \mathrm{~mL}$ of either M9+succinate or LB in a $250 \mathrm{~mL}$ flask and incubated statically (without aeration) for $22 \mathrm{~h}$ at $37^{\circ} \mathrm{C}$ (Fig. 3C). From the resulting cultures, $4 \mathrm{ODs}$ were collected and considered "output." Plasmid content from "input" and "output" was extracted by Nucleospin Mini plasmid kit (Macherey-Nagel) and used as template for library preparation for deep sequencing as detailed below.

Library preparation was carried out by using $50 \mathrm{ng}$ of plasmid as template from the "input" and "output." For each library, LIB1 
(1-81 aa), LIB2 (73-155 aa), and LIB3 (155-227 aa), same region subjected to mutagenesis was amplified by PCR with specific primers that incorporated Nextera adapters: (i) JVO18138/ JVO18139 for LIB1, (ii) JVO18140/JVO18141 for LIB2, and (iii) JVO18142/JVO18143 for LIB3. The distribution of the library and concentration of library DNA was determined by DNA bioanalyzer and a DNA Qubit measurement, respectively. Amplified DNAs from different libraries were pooled and sequenced on an Illumina Mi-seq pair ended $300 \mathrm{bp}$ at the Next generation sequencing core unit of the Helmholtz Centre for Infection Biology $(\mathrm{HZI})$.

\section{Deep mutational scanning data analysis}

Deep mutational scanning generated read counts were analyzed by applying the Enrich2 statistical framework (Rubin et al. 2017). Shortly, for each library, read counts were mapped to ProQ mutagenized region LIB1 (1-81 aa), LIB2 (73-155 aa), and LIB3 (155227 aa), respectively. Enrichment factors were calculated between the "output" and "input" libraries in M9 succinate (one biological duplicate each) and in LB (Fowler et al. 2014; Rubin et al. 2017). The reads were used as input for Enrich2 (Rubin et al. 2017) to determine enrichment of point mutations. For this, Enrich2 settings were set to include reads with an average read quality above 20 and up to 50 mismatches to the ProO sequence, and unmatched paired reads were excluded. The enrichment scores and Z-scores (deviation from the overall mean) were calculated using the setting "log ratios (Enrich2)" after normalization to the detected wild-type sequences.

\section{RNA-coimmunoprecipitation}

RNA-coimmunoprecipitation was carried out as previously described. Salmonella enterica WT and derivative $\Delta$ lon strains carrying either a vector control (VC), pProQ-3×FLAG WT or pProQ-3×FLAG R80A variants were grown in $L B$ to $O_{600} \mathrm{~nm}$ 2.0. A volume of cells representing 50 ODs were pelleted and cells resuspended in $800 \mu \mathrm{L}$ of lysis buffer $(20 \mathrm{mM}$ Tris pH8.0, $150 \mathrm{mM} \mathrm{KCl}, 1 \mathrm{mM} \mathrm{MgCl} 2,1 \mathrm{mM}$ DTT) supplemented with $8 \mu \mathrm{L}$ of DNase I. The cells were lysed through mechanical lysis by 0.1 $\mathrm{mm}$ glass beads at $30 \mathrm{~Hz}$ for $10 \mathrm{~min}$ in the Retsch MM200. The lysate was cleared by centrifugation. For protein input control, a volume equivalent to $0.5 \mathrm{OD}_{600 \mathrm{~nm}}$ was diluted to $90 \mu \mathrm{L}$ with $1 \times$ Laemmli buffer (lysate protein sample) and stored at $-20^{\circ} \mathrm{C}$. For RNA input control, a volume equivalent to $5 \mathrm{OD}_{600 \mathrm{~nm}}$ was saved for RNA extraction with TRIzol (lysate RNA sample). The remaining lysate was then incubated with $25 \mu \mathrm{L}\left(1 \mu \mathrm{L} / 2 \mathrm{OD}_{600 \mathrm{~nm}}\right.$ of cells) of monoclonal anti-FLAG M2 (Sigma \#F1804) at $4^{\circ} \mathrm{C}$ with rotation for $30 \mathrm{~min}$. The sample was then added to $75 \mu \mathrm{L}$ of prewashed Protein A sepharose beads (Sigma-Aldrich) and further incubated with rotation at $4^{\circ} \mathrm{C}$ for an additional $30 \mathrm{~min}$. The beads were washed with $500 \mu \mathrm{L}$ of lysis buffer for five times and finally resuspended in $532 \mu \mathrm{L}$ of lysis buffer for elution of ProQ $3 \times$ FLAG variants and coimmunoprecipitated RNA.

For protein elution control, to a volume of $32 \mu \mathrm{L}, 8 \mu \mathrm{L}$ of $5 \times$ Laemmli buffer was added and stored at $-20^{\circ} \mathrm{C}$ (elution protein sample). For RNA elution, coimmunoprecipitated RNA was extracted by phenol:chloroform:isoamyl alcohol (P:C:I) (25:24:1, $\mathrm{pH} 4.5$, Roth) extraction. The purified RNA samples were treated by DNase I and subsequently purified by P:C:I extraction. Samples were resuspended in $\mathrm{H}_{2} \mathrm{O}$ to a final concentration of $1 \mathrm{OD} / \mu \mathrm{L}$ for elution samples and $0.1 \mathrm{OD} / \mu \mathrm{L}$ for lysate, flowthrough and wash. Resulting RNA samples were subjected to visualization via northern blot or quantification via deep sequencing. Protein extracts were also analyzed by western blot.

\section{cDNA library preparation and RIP-seq data analysis}

Library preparation from coimmunoprecipitated RNA samples was carried out with NEBNext Multiplex Small RNA Library Prep Set (New England Biolabs), which allows sequencing in Illumina platforms. The library preparation was carried out in a thermocycler, and manufacturer's guidelines were followed with minor modifications as previously described (El Mouali et al. 2021). The distribution of the library and concentration of library DNA were determined by a DNA bioanalyzer and a DNA Qubit measurement, respectively. Amplified cDNAs from different libraries were pooled and sequenced on an Illumina NextSeq 500 platform at the Core Unit SysMed at the University of Würzburg. Mapping and quantification was performed as previously described (El Mouali et al. 2021). The enrichment of RNA was calculated by comparing coenriched RNA with ProQ-3×FLAG WT and ProQ-3×FLAG R80A protein variants to the vector control (VC) strain. This experiment was performed in biological duplicates (Supplemental Table S3).

\section{DATA DEPOSITION}

The sequencing data have been deposited in the NCBI Gene Expression Omnibus (Edgar et al. 2002) and are accessible through GEO Series accession number GSE174509.

\section{SUPPLEMENTAL MATERIAL}

Supplemental material is available for this article.

\section{NOTE ADDED IN PROOF}

Since this study was accepted for publication, the Holmqvist laboratory published an independent global mutagenesis study of the Salmonella ProQ protein in vivo (Rizvanovic et al. 2021). This independent study also concludes a role of ProQ CTD in gene regulation, which supports our findings on ProQ CTD being required for in vivo function on succinate utilization regulation in Salmonella. In addition, it also reports that mutations within the FinO domain that preclude RNA binding affect ProQ protein levels, which further supports our working model of ProQ clearance from the cells by the protease Lon when ProQ fails to bind RNA.

\section{ACKNOWLEDGMENTS}

We thank Jens Hör, Gianluca Matera, and Susan Gottesman for fruitful discussions. We are grateful to Svetlana Durica-Mitic and Gianluca Matera for critical reading of the manuscript. We thank Eduardo Groisman and Josep Casadesus for providing strains. We appreciated advice on Lon-mediated degradation from 
Franz Narberhaus and Simon Brückner. We thank the Vogel Stiftung Dr. Eckernkamp for supporting F.P. with a Dr. Eckernkamp Fellowship. This work was supported by a DFG Leibniz Award to J.V. (Vo875-18), and, in part, by a Wellcome Trust Senior Investigator award to J.C.D.H. (grant number $106914 / Z / 15 / Z)$. For the purpose of open access, the author has applied a CC BY public copyright license to any Author Accepted Manuscript version arising from this submission.

Received August 17, 2021; accepted August 24, 2021.

\section{REFERENCES}

Attaiech L, Boughammoura A, Brochier-Armanet C, Allatif O, PeillardFiorente F, Edwards RA, Omar AR, MacMillan AM, Glover M, Charpentier X. 2016. Silencing of natural transformation by an RNA chaperone and a multitarget small RNA. Proc Natl Acad Sci 113: 8813-8818. doi:10.1073/pnas. 1601626113

Basu P, Elgrably-Weiss M, Hassouna F, Kumar M, Wiener R, Altuvia S. 2021. RNA binding of Hfq monomers promotes RelA-mediated hexamerization in a limiting $\mathrm{Hfq}$ environment. Nat Commun 12: 2249. doi:10.1038/s41467-021-22553-x

Bauriedl S, Gerovac M, Heidrich N, Bischler T, Barquist L, Vogel J, Schoen C. 2020. The minimal meningococcal ProQ protein has an intrinsic capacity for structure-based global RNA recognition. Nat Commun 11: 2823. doi:10.1038/s41467-020-16650-6

Chao Y, Papenfort K, Reinhardt R, Sharma CM, Vogel J. 2012. An atlas of $\mathrm{Hfq}$-bound transcripts reveals $3^{\prime}$ UTRs as a genomic reservoir of regulatory small RNAs. EMBO J 31: 4005-4019. doi:10.1038/ emboj.2012.229

Chaulk SG, Smith-Frieday MN, Arthur DC, Culham DE, Edwards RA, Soo P, Frost LS, Keates RAB, Glover JNM, Wood JM. 2011. ProQ is an RNA chaperone that controls ProP levels in Escherichia coli. Biochemistry 50: 3095-3106. doi:10.1021/ bi101683a

Cherepanov PP, Wackernagel W. 1995. Gene disruption in Escherichia coli: TcR and KmR cassettes with the option of Flp-catalyzed excision of the antibiotic-resistance determinant. Gene 158: 9-14. doi:10.1016/0378-1119(95)00193-A

Choi J, Groisman EA. 2020. Salmonella expresses foreign genes during infection by degrading their silencer. Proc Natl Acad Sci 117: 8074-8082. doi:10.1073/pnas.1912808117

Chung CH, Goldberg AL. 1981. The product of the lon (capR) gene in Escherichia coli is the ATP-dependent protease, protease La. Proc Natl Acad Sci 78: 4931-4935. doi:10.1073/pnas.78.8.4931

Datsenko KA, Wanner BL. 2000. One-step inactivation of chromosomal genes in Escherichia coli K-12 using PCR products. Proc Natl Acad Sci 97: 6640-6645. doi:10.1073/pnas.120163297

Edgar R, Domrachev M, Lash AE. 2002. Gene Expression Omnibus: $\mathrm{NCBI}$ gene expression and hybridization array data repository. Nucleic Acids Res 30: 207-210. doi:10.1093/nar/30.1.207

El Mouali Y, Gerovac M, Mineikaite R, Vogel J. 2021. In vivo targets of Salmonella FinO include a FinP-like small RNA controlling copy number of a cohabitating plasmid. Nucleic Acids Res 49: 5319-5335. doi:10.1093/nar/gkab281

Fernandez L, Breidenstein EBM, Taylor PK, Bains M, De La FuenteNunez C, Fang Y, Foster LJ, Hancock REW. 2016. Interconnection of post-transcriptional regulation: the RNA-binding protein $\mathrm{Hfq}$ is a novel target of the Lon protease in Pseudomonas aeruginosa. Sci Rep 6: 26811. doi:10.1038/srep26811

Fowler DM, Stephany JJ, Fields S. 2014. Measuring the activity of protein variants on a large scale using deep mutational scanning. Nat Protoc 9: 2267-2284. doi:10.1038/nprot.2014.153
Gao X, Yeom J, Groisman EA. 2019. The expanded specificity and physiological role of a widespread N-degron recognin. Proc Natl Acad Sci 116: 18629-18637. doi:10.1073/pnas.1821060116

Gerovac M, Mouali YEL, Kuper J, Kisker C, Barquist L, Vogel J. 2020. Global discovery of bacterial RNA-binding proteins by RNase-sensitive gradient profiles reports a new FinO domain protein. RNA 26: 1448-1463. doi:10.1261/rna.076992.120

Ghetu AF, Gubbins MJ, Oikawa K, Kay CM, Frost LS, Glover JN. 1999. The FinO repressor of bacterial conjugation contains two RNA binding regions. Biochemistry 38: 14036-14044. doi:10.1021/ bi9911482

Gonzalez GM, Hardwick SW, Maslen SL, Skehel JM, Holmqvist E, Vogel J, Bateman A, Luisi BF, Broadhurst RW. 2017. Structure of the Escherichia coli ProQ RNA-binding protein. RNA 23: 696711. doi:10.1261/rna.060343.116

Gorski SA, Vogel J, Doudna JA. 2017. RNA-based recognition and targeting: sowing the seeds of specificity. Nat Rev Mol Cell Biol 18: 215-228. doi:10.1038/nrm.2016.174

Gottesman S. 1996. Proteases and their targets in Escherichia coli. Annu Rev Genet 30: 465-506. doi:10.1146/annurev.genet.30.1 .465

Gottesman S, Maurizi MR. 1992. Regulation by proteolysis: energydependent proteases and their targets. Microbiol Rev 56: 592 621. doi:10.1128/mr.56.4.592-621.1992

Gur E, Biran D, Ron EZ. 2011. Regulated proteolysis in Gram-negative bacteria-how and when? Nat Rev Microbiol 9: 839-848. doi:10 .1038/nrmicro2669

Hankins JS, Denroche H, Mackie GA. 2010. Interactions of the RNAbinding protein $\mathrm{Hfq}$ with $\operatorname{cspA} \mathrm{mRNA}$, encoding the major cold shock protein. J Bacteriol 192: 2482-2490. doi:10.1128/JB .01619-09

Heidrich N, Bauriedl S, Barquist L, Li L, Schoen C, Vogel J. 2017. The primary transcriptome of Neisseria meningitidis and its interaction with the RNA chaperone Hfq. Nucleic Acids Res 45: 6147-6167.

Hersch SJ, Radan B, llyas B, Lavoie P, Navarre WW. 2021. Stress-induced block in dicarboxylate uptake and utilization in Salmonella enterica serovar typhimurium. J Bacteriol 203: e00487-20. doi:10.1128/JB.00487-20

Hoiseth SK, Stocker BAD. 1981. Aromatic-dependent Salmonella typhimurium are non-virulent and effective as live vaccines. Nature 291: 238-239. doi:10.1038/291238a0

Holmqvist E, Vogel J. 2018. RNA-binding proteins in bacteria. Nat Rev Microbiol 16: 601-615. doi:10.1038/s41579-018-0049-5

Holmqvist E, Wright PR, Li L, Bischler T, Barquist L, Reinhardt R, Backofen R, Vogel J. 2016. Global RNA recognition patterns of post-transcriptional regulators $\mathrm{Hfq}$ and CsrA revealed by UV crosslinking in vivo. EMBO J 35: 991-1011. doi:10.15252/embj .201593360

Holmqvist E, Li L, Bischler T, Barquist L, Vogel J. 2018. Global maps of ProQ binding in vivo reveal target recognition via RNA structure and stability control at mRNA $3^{\prime}$ ends. Mol Cell 70: 971-982.e6. doi:10.1016/j.molcel.2018.04.017

Holmqvist E, Berggren S, Rizvanovic A. 2020. RNA-binding activity and regulatory functions of the emerging sRNA-binding protein ProQ. Biochim. Biophys Acta Gene Regul Mech 1863: 194596. doi:10.1016/j.bbagrm.2020.194596

losub IA, van Nues RW, McKellar SW, Nieken KJ, Marchioretto M, Sy B, Tree JJ, Viero G, Granneman S. 2020. Hfq CLASH uncovers sRNA-target interaction networks linked to nutrient availability adaptation. Elife 9: e54655. doi:10.7554/eLife.54655

Jiang L, Wang P, Song X, Zhang H, Ma S, Wang J, Li W, Lv R, Liu X, $\mathrm{Ma} S$, et al. 2021. Salmonella Typhimurium reprograms macrophage metabolism via T3SS effector SopE2 to promote intracellular replication and virulence. Nat Commun 12: 879. doi:10.1038/ s41467-021-21186-4 
Kavita K, de Mets F, Gottesman S. 2018. New aspects of RNA-based regulation by $\mathrm{Hfq}$ and its partner sRNAs. Curr Opin Microbiol 42: 53-61. doi:10.1016/j.mib.2017.10.014

Lee I, Suzuki CK. 2008. Functional mechanics of the ATP-dependent Lon protease-lessons from endogenous protein and synthetic peptide substrates. Biochim Biophys Acta Proteins Proteomics 1784: 727-735. doi:10.1016/j.bbapap.2008.02.010

Melamed S, Peer A, Faigenbaum-Romm R, Gatt YE, Reiss N, Bar A, Altuvia Y, Argaman L, Margalit H. 2016. Global mapping of small RNA-target interactions in bacteria. Mol Cell 63: 884-897. doi:10.1016/j.molcel.2016.07.026

Melamed S, Adams PP, Zhang A, Zhang H, Storz G. 2020. RNA-RNA interactomes of ProO and $\mathrm{Hfq}$ reveal overlapping and competing roles. Mol Cell 77: 411-425.e7. doi:10.1016/j.molcel.2019.10.022

Mikulecky PJ, Kaw MK, Brescia CC, Takach JC, Sledjeski DD, Feig AL. 2004. Escherichia coli $\mathrm{Hfq}$ has distinct interaction surfaces for DsrA, rpoS and poly(A) RNAs. Nat Struct Mol Biol 11: 12061214. doi: $10.1038 / \mathrm{nsmb} 858$

Milner JL, Wood JM. 1989. Insertion proQ220::Tn5 alters regulation of proline porter II, a transporter of proline and glycine betaine in Escherichia coli. J Bacteriol 171: 947-951. doi:10.1128/jb.171 2.947-951.1989

Olejniczak M, Storz G. 2017. ProQ/FinO-domain proteins: another ubiquitous family of RNA matchmakers? Mol Microbiol 104: 905-915. doi:10.1111/mmi.13679

Pandey S, Gravel CM, Stockert OM, Wang CD, Hegner CL, LeBlanc H, Berry KE. 2020. Genetic identification of the functional surface for RNA binding by Escherichia coli ProQ. Nucleic Acids Res 48: 4507-4520. doi:10.1093/nar/gkaa144

Panja S, Woodson SA. 2012. Hexamer to monomer equilibrium of $E$. coli $\mathrm{Hfq}$ in solution and its impact on RNA annealing. J Mol Biol 417: 406-412. doi:10.1016/j.jmb.2012.02.009

Panja S, Santiago-Frangos A, Schu DJ, Gottesman S, Woodson SA. 2015. Acidic residues in the $\mathrm{Hfq}$ chaperone increase the selectivity of sRNA binding and annealing. J Mol Biol 427: 3491-3500. doi:10.1016/j.jmb.2015.07.010

Potts AH, Vakulskas CA, Pannuri A, Yakhnin H, Babitzke P, Romeo T. 2017. Global role of the bacterial post-transcriptional regulator CsrA revealed by integrated transcriptomics. Nat Commun 8: 1596. doi:10.1038/s41467-017-01613-1

Rizvanovic A, Kjellin J, Söderbom F, Holmqvist E. 2021. Saturation mutagenesis charts the functional landscape of Salmonella ProO and reveals a gene regulatory function of its C-terminal domain. Nucleic Acids Res doi:10.1093/nar/gkab721

Romeo T, Babitzke P. 2018. Global regulation by CsrA and its RNA antagonists. Microbiol Spectr 6. doi:10.1128/microbiolspec.RWR0009-2017

Rosenberg G, Yehezkel D, Hoffman D, Ciolli Mattioli C, Fremder M, Ben-Arosh H, Vainman L, Nissani N, Hen-Avivi S, Brenner S, et al. 2021. Host succinate is an activation signal for Salmonella virulence during intracellular infection. Science 371: 400-405. doi:10 .1126/science.aba8026

Rubin AF, Gelman H, Lucas N, Bajjalieh SM, Papenfuss AT, Speed TP, Fowler DM. 2017. A statistical framework for analyzing deep mutational scanning data. Genome Biol 18: 150. doi:10.1186/s13059017-1272-5

Sauer E, Schmidt S, Weichenrieder O. 2012. Small RNA binding to the lateral surface of $\mathrm{Hfq}$ hexamers and structural rearrangements upon mRNA target recognition. Proc Natl Acad Sci 109: 93969401. doi:10.1073/pnas.1202521109

Sauerbrei B, Arends J, Schünemann D, Narberhaus F. 2020. Lon protease removes excess signal recognition particle protein in Escherichia coli. J Bacteriol 202: e00161-20. doi:10.1128/JB $.00161-20$
Schoemaker JM, Gayda RC, Markovitz A. 1984. Regulation of cell division in Escherichia coli: SOS induction and cellular location of the SulA protein, a key to lon-associated filamentation and death. J Bacteriol 158: 551-561. doi:10.1128/jb.158.2.551-561 1984

Schu D, Zhang A, Gottesman S, Storz G. 2015. Alternative Hfq-sRNA interaction modes dictate alternative mRNA recognition. EMBO J 34: 2557-2573.

Serna A, Espinosa E, Camacho EM, Casadesús J. 2010. Regulation of bacterial conjugation in microaerobiosis by host-encoded functions $A r c A B$ and SdhABCD. Genetics 184: 947-958. doi:10 $.1534 /$ genetics.109.109918

Shah IM, Wolf RE. 2006. Sequence requirements for Lon-dependent degradation of the Escherichia coli transcription activator SoxS: identification of the SoxS residues critical to proteolysis and specific inhibition of in vitro degradation by a peptide comprised of the $\mathrm{N}$-terminal 21 amino acid residues. J Mol Biol 357: 718-731. doi:10.1016/j.jmb.2005.12.088

Simon LD, Gottesman M, Tomczak K, Gottesman S. 1979. Hyperdegradation of proteins in Escherichia coli rho mutants. Proc Natl Acad Sci 76: 1623-1627. doi:10.1073/pnas .76.4.1623

Sittka A, Pfeiffer V, Tedin K, Vogel J. 2007. The RNA chaperone Hfq is essential for the virulence of Salmonella Typhimurium. Mol Microbiol 63: 193-217. doi:10.1111/j.1365-2958.2006.05489.x

Sittka A, Lucchini S, Papenfort K, Sharma CM, Rolle K, Binnewies TT, Hinton JCD, Vogel J. 2008. Deep sequencing analysis of small noncoding RNA and mRNA targets of the global post-transcriptional regulator, Hfq. PLoS Genet 4: e1000163. doi:10.1371/jour nal.pgen.1000163

Smirnov A, Förstner KU, Holmqvist E, Otto A, Günster R, Becher D, Reinhardt R, Vogel J. 2016. Grad-seq guides the discovery of ProO as a major small RNA-binding protein. Proc Natl Acad Sci 113: 11591-11596. doi:10.1073/pnas. 1609981113

Spiga L, Winter M, Furtado de Carvalho T, Zhu W, Hughes E, Gillis C, Behrendt C, Kim J, Chessa D, Andrews-Polymenis H, et al. 2017. An oxidative central metabolism enables Salmonella to utilize microbiota-derived succinate. Cell Host Microbe 22: 291-301. e6. doi:10.1016/j.chom.2017.07.018

Stalmach ME, Grothe S, Wood JM. 1983. Two proline porters in Escherichia coli K-12. J Bacteriol 156: 481-486. doi:10.1128/jb $.156 .2 .481-486.1983$

Stein EM, Kwiatkowska J, Basczok MM, Gravel CM, Berry KE, Olejniczak M. 2020. Determinants of RNA recognition by the FinO domain of the Escherichia coli ProQ protein. Nucleic Acids Res 48: 7502-7519. doi:10.1093/nar/gkaa497

Torres-Cabassa AS, Gottesman S. 1987. Capsule synthesis in Escherichia coli K-12 is regulated by proteolysis. J Bacteriol 169: 981-989. doi:10.1128/jb.169.3.981-989.1987

Tree JJ, Granneman S, McAteer SP, Tollervey D, Gally DL. 2014. Identification of bacteriophage-encoded anti-sRNAs in pathogenic Escherichia coli. Mol Cell 55: 199-213. doi:10.1016/j .molcel.2014.05.006

Van Dijl JM, Kutejová E, Suda K, Perečko D, Schatz G, Suzuki CK. 1998. The ATPase and protease domains of yeast mitochondrial Lon: roles in proteolysis and respiration-dependent growth. Proc Natl Acad Sci 95: 10584-10589. doi:10.1073/pnas.95.18.10584

Van Melderen L, Bernard P, Couturier M. 1994. Lon-dependent proteolysis of $\mathrm{CcdA}$ is the key control for activation of $\mathrm{CcdB}$ in plasmidfree segregant bacteria. Mol Microbiol 11: 1151-1157. doi:10 .1111/j.1365-2958.1994.tb00391.x

Van Melderen L, Thi MHD, Lecchi P, Gottesman S, Couturier M, Maurizi MR. 1996. ATP-dependent degradation of CcdA by Lon protease. Effects of secondary structure and heterologous subunit 
interactions. J Biol Chem 271: 27730-27738. doi:10.1074/jbc.271 .44 .27730

Vogel J, Luisi BF. 2011. Hfq and its constellation of RNA. Nat Rev Microbiol 9: 578-589. doi:10.1038/nrmicro2615

Westermann AJ, Venturini E, Sellin ME, Förstner KU, Hardt WD, Vogel J. 2019. The major RNA-binding protein ProQ impacts virulence gene expression in Salmonella enterica serovar Typhimurium. MBio 10: e02504-18. doi:10.1128/mBio.02504-18
Zhang A, Wassarman KM, Rosenow C, Tjaden BC, Storz G, Gottesman S. 2003. Global analysis of small RNA and mRNA targets of Hfq. Mol Microbiol 50: 1111-1124. doi:10.1046/j.13652958.2003.03734.x

Zhang A, Schu DJ, Tjaden BC, Storz G, Gottesman S. 2013. Mutations in interaction surfaces differentially impact $E$. coli $\mathrm{Hfq}$ association with small RNAs and their mRNA targets. J Mol Biol 425: 36783697. doi:10.1016/j.jmb.2013.01.006 

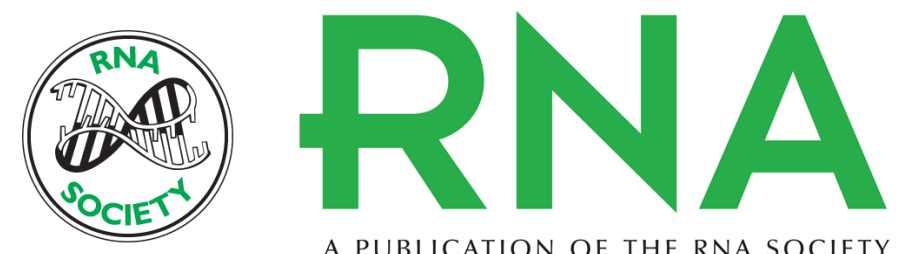

A PUBLICATION OF THE RNA SOCIETY

\section{Scanning mutagenesis of RNA-binding protein ProQ reveals a quality control role for the Lon protease}

Youssef El Mouali, Falk Ponath, Vinzent Scharrer, et al.

RNA 2021 27: 1512-1527 originally published online September 8, 2021

Access the most recent version at doi:10.1261/rna.078954.121

\section{Supplemental http://rnajournal.cshlp.org/content/suppl/2021/09/08/rna.078954.121.DC1 Material}

References This article cites 68 articles, 23 of which can be accessed free at: http://rnajournal.cshlp.org/content/27/12/1512.full.html\#ref-list-1

Open Access Freely available online through the RNA Open Access option.

Creative This article, published in $R N A$, is available under a Creative Commons License Commons (Attribution-NonCommercial 4.0 International), as described at License http://creativecommons.org/licenses/by-nc/4.0/.

Email Alerting Receive free email alerts when new articles cite this article - sign up in the box at the Service top right corner of the article or click here.

\section{|||||||| Providing Precise Solutions for your research.}

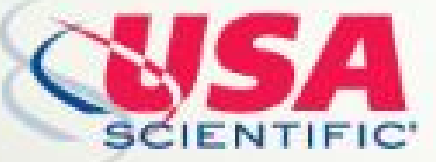

To subscribe to $R N A$ go to:

http://rnajournal.cshlp.org/subscriptions

(C) 2021 El Mouali et al.; Published by Cold Spring Harbor Laboratory Press for the RNA Society 